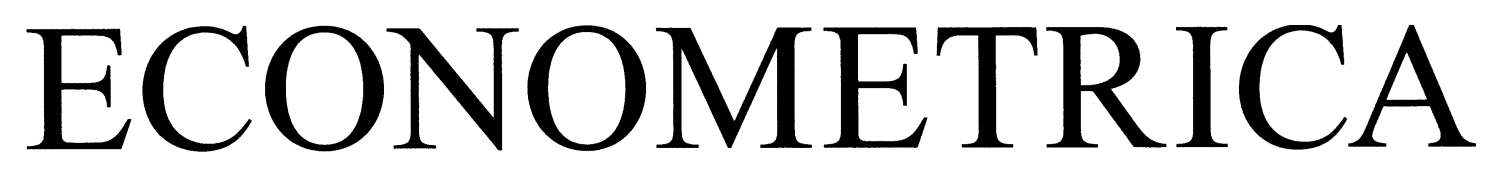

JOURNAL OF THE ECONOMETRIC SOCIETY

An International Society for the Advancement of Economic Theory in its Relation to Statistics and Mathematics

http://www.econometricsociety.org/

Econometrica, Vol. 80, No. 6 (November, 2012), 2469-2509

CAPITAL MOBILITY AND ASSET PRICING

DARRELL DUFFIE

Graduate School of Business, Stanford University, Stanford, CA 94305, U.S.A.

BRUNO STRULOVICI

Northwestern University, Evanston, IL 60208, U.S.A.

The copyright to this Article is held by the Econometric Society. It may be downloaded, printed and reproduced only for educational or research purposes, including use in course packs. No downloading or copying may be done for any commercial purpose without the explicit permission of the Econometric Society. For such commercial purposes contact the Office of the Econometric Society (contact information may be found at the website http://www.econometricsociety.org or in the back cover of Econometrica). This statement must be included on all copies of this Article that are made available electronically or in any other format. 


\title{
CAPITAL MOBILITY AND ASSET PRICING
}

\author{
By DARREll DUfFIE AND BRUNO STRULOVICI ${ }^{1}$
}

\begin{abstract}
We present a model for the equilibrium movement of capital between asset markets that are distinguished only by the levels of capital invested in each. Investment in that market with the greatest amount of capital earns the lowest risk premium. Intermediaries optimally trade off the costs of intermediation against fees that depend on the gain they can offer to investors for moving their capital to the market with the higher mean return. The bargaining power of an investor depends on potential access to alternative intermediaries. In equilibrium, the speeds of adjustment of mean returns and of capital between the two markets are increasing in the degree to which capital is imbalanced between the two markets, and can be reduced by competition among intermediaries.
\end{abstract}

KEYWORDS: Capital mobility, market frictions, financial intermediation, law of one price.

\section{INTRODUCTION}

WE PRESENT A MODEL for the equilibrium movement of capital between two partially segmented markets that are identical except for the amounts of capital invested in each. Equilibrium conditional mean rates of return vary across the markets according to the levels of capital invested in the respective markets. As a matter of supply and demand within each market, that market with the greater amount of capital earns lower conditional mean returns. Given a sufficient disparity in the capital levels in the markets, intermediaries find it optimal to search for investors in the market with "surplus" capital and offer them the opportunity to move their capital to the other market, which offers higher risk premia. Intermediaries charge investors a fee that is based on their gain from the move and based on the degree of competition in the market for intermediation. The equilibrium behavior of intermediaries is solved analytically, and characterized. Increased competition among intermediaries can in some cases reduce capital mobility.

In our equilibrium model, the greater the heterogeneity in capital levels across the markets, the more intensive are intermediaries' efforts to rebalance the distribution of capital across the markets, and the greater is the rate of convergence of the mean rates of return of different assets toward a common

\footnotetext{
${ }^{1}$ We are grateful for reactions at Oxford University, the Gerzensee European Summer Symposium in Financial Markets, the University of Toulouse, The London School of Economics, London Business School, Yale University, NBER Asset Pricing Conference, Columbia University, Northwestern University, and especially for comments from Bruno Biais, Eddie Dekel, Julien Hugonnier, Jean-Charles Rochet, Larry Samuelson, Avanidhar (Subra) Subrahmanyam, Jean Tirole, Dimitri Vayanos, and Glen Weyl. The advice of the editor and several anonymous referees was very useful. We are thankful for the research assistance of Sergey Lobanov and Felipe Veras. Strulovici acknowledges financial support from the National Science Foundation Grant 1151410.
} 
level. We study the impact on capital mobility of search costs, discounting, asset volatility, and other parameters.

This model is motivated by empirical evidence, some of which is reviewed in the last section. The evidence is that supply or demand shocks in asset markets, in addition to causing an immediate price response, also lead to adjustments over time in the distribution of capital across markets and adjustments over time in relative conditional mean asset returns. This asset price behavior reflects delays in the adjustments of investors' portfolios. We are particularly interested in how those adjustments are affected by the behavior of intermediaries.

An example is the limited mobility of capital into reinsurance markets, documented by Froot and O'Connell (1999), who wrote: “Our results suggest that capital market imperfections are more important than shifts in actuarial valuation for understanding catastrophe reinsurance pricing. Supply, rather than demand, shifts seem to explain most features of the market in the aftermath of a loss." In subsequent work, Froot (2001) continued: "We ... find the most compelling (evidence) to be supply restrictions associated with capital market imperfections and market power exerted by traditional reinsurers."

A significant body of theory examines the implications of search frictions for asset pricing. For example, differences in search frictions across different asset markets were treated by Weill (2008) and Vayanos and Wang (2007). Duffie, Gârleanu, and Pedersen (2005) studied the implications of search frictions in a single asset market with market making. In the context of a single asset market, Duffie, Gârleanu, and Pedersen (2007) and Lagos, Rocheteau, and Weill (2011) modeled recoveries in mean returns after a shock to the preferences of investors, corresponding to a gradual reallocation of the asset to more suitable investors, rather than by cross-market capital dynamics as here. Earlier search-based models of intermediation include those of Rubinstein and Wolinsky (1987), Bhattacharya and Hagerty (1987), Moresi (1991), Gehrig (1993), and Yavaş (1996).

Related work on the implications of capital market frictions for asset pricing dynamics includes the models of Basak and Croitoru (2000) and He and Krishnamurthy (2012). In terms of some objectives and model features, independent work by Gromb and Vayanos (2012) is closely related to ours. Common to our models, local hedgers are immobile, while arbitrageurs can work across markets, driving returns toward fundamental levels, subject to frictions that prevent them from perfectly equating returns in the two markets. Our respective approaches, however, are quite different. We focus on the dynamics of intermediation, capital movements, and risk premia.

We offer a quick synopsis of the model and results. In each of two markets that are partially segmented from each other, a continuum of risk-neutral investors earn a mean rate of return that is strictly decreasing in the total amount of capital invested in that market. Segmentation of the two markets arises from the limited capacity of intermediaries to contact individual investors in 
the "over-capitalized" market and arrange for the movement of their capital to the "under-capitalized" market, where they can currently earn higher returns. Intermediaries charge investors a fee for this service. The fee is a fraction of the gain in present value of future net payoffs to the investor that is achieved by the reallocation of capital. The investor and intermediary bear in mind that, due to the lack of perfect correlation in the future investment returns in the two markets, the market that is currently relatively over-capitalized may later become relatively under-capitalized, at which point the investor will wish to reallocate his or her capital to the original market, and so on. Intermediation costs are increasing in the effort made to contact investors. For each investor, the conditional mean arrival intensity of contacts with the intermediary is strictly increasing in the effort of the intermediary. Intermediaries are assumed to be unable to commit to their future intermediation effort policy. In equilibrium, naturally, intermediation efforts are increasing in the degree to which capital is imbalanced across the two markets. Thus, the difference in the conditional mean returns of the two markets is mean-reverting. In the simplest parametric examples that we consider, intermediation efforts are minimal whenever the ratio of capital in the over-capitalized market to capital in the under-capitalized market is below a threshold that is characterized analytically, and is maximal otherwise.

We are particularly interested in the impact of competition among intermediaries on the equilibrium degree of capital mobility, through two channels. First, an intermediary does not internalize the entire impact of its search effort on leveling the distribution of capital across markets because each intermediary gets only a fraction of the aggregate intermediation fees. This prompts intermediaries to search more as the number of intermediaries increases, all else equal. Competition among intermediaries has a second and potentially offsetting effect on capital mobility through the impact of fee bargaining on incentives to intermediate. We outline a model in which, as the number of intermediaries increases, but aggregate search capacity is kept constant, the bargaining power of each intermediary is reduced. We show that the second effect of competition, through reduced bargaining power, can dominate, so that in some cases increasing the number of intermediaries reduces capital mobility.

Section 2 describes the market setting. Sections 3 and 4 analyze the monopolistic and oligopolistic intermediation cases, respectively. Section 5 summarizes the implications of our model for asset-price dynamics and provides some evidence regarding the premise or implications of our model. Proofs and several extensions of the model are found in the appendices. Appendices D through L are located in Duffie and Strulovici (2012), the Supplemental Material to this paper.

\section{THE MARKET SETTING}

This section presents a stylized model for the endogenous adjustment of capital and risk premia across markets. There are three types of agents: (i) local 
hedgers; (ii) investors who provide risk-bearing to hedgers in each of two local markets; and (iii) intermediaries (such as asset managers) who provide the fee-based service to investors of moving capital from one market to another.

We fix a probability space $(\Omega, \mathcal{F}, P)$ and a common information filtration $\left\{\mathcal{F}_{t}: t \in[0, \infty)\right\}$ satisfying the usual conditions. ${ }^{2}$

In each of two financial markets, labeled $a$ and $b$, a continuum (a non-atomic measure space) of local risk-averse agents own short-lived risky assets. These "hedgers" are not mobile across markets. They can be viewed in this respect as relatively unsophisticated in the use of cross-capital-market transactions, or as having high transactions costs for trading outside of their local markets. A continuum of investors that supply capital have access to cross-market trading, subject to intermediation frictions to be described. These suppliers of capital are risk-neutral, and are therefore willing to invest in the risky assets that hedgers sell, provided the risk premium is strictly positive. In an insurance context, one might think of these suppliers of capital as stylized versions of the "Names" that supply risk-bearing capacity to the insurance market known as "Lloyd's of London."

The total levels of capital available in the two markets at time $t$ are $X_{a t}$ and $X_{b t}$, respectively. Capital can be reinvested continually in time, at the discretion of each investor, in the short-lived assets that are continually made available for sale by hedgers. Each unit of capital that is currently invested in market $i$ at time $t$ is paid cash at the equilibrium dividend rate $\pi\left(X_{i t}\right)$, where $\pi(\cdot)$ is a strictly decreasing continuous function. The dividend rate $\pi\left(X_{i t}\right)$ is continually reset in double auctions at which the supply and demand for the asset in market $i$ are matched at each point in time. In Appendix D, we provide an example in which $\pi(x)$ is the equilibrium insurance premium in a market with $x$ units of insurance capital.

In return for the dividend rate $\pi\left(X_{i t}\right)$, the provider of each unit of capital in market $i$ agrees to absorb proportional losses of capital at loss events that arrive according to a Poisson process. The proportional losses of different events are independently and identically distributed. That is, the cumulative proportional loss in market $i$ is a compound Poisson process $\rho_{i}$. (We later extend some of our basic results to allow $\rho_{i}$ to be a general Lévy process, allowing, for example, some role for the diffusive action of Brownian motions.) One unit of capital invested at time $t$ therefore pays the supplier of capital $1+\pi\left(X_{i t}\right) d t$ at time $t+d t$, in the usual "instantaneous" sense, if there is no loss event, and if there is a loss event, has a recovery value of $1+\Delta \rho_{i t}$, where $\Delta \rho_{i t}$ is the jump size. The jumps of $\rho_{i}$ are bounded below by -1 , preserving limited liability. The loss events have a mean arrival rate $\eta$ and a loss-size distribution $\nu$ with mean $\bar{\nu}$, so the mean loss rate is $\eta \bar{\nu}$. The risk-neutral investors therefore optimally supply all of their local capital inelastically so long as the mean rate of return

\footnotetext{
${ }^{2}$ See, for example, Protter (2004) for the usual conditions and for other standard properties of stochastic processes to which we refer.
} 
$\pi(x)-\eta \bar{\nu}$ is strictly larger than their time preference rate $r$. This necessary condition on an equilibrium cash payout function $\pi(\cdot)$ is satisfied in the cases that we examine, as indicated in Appendix A.

Cash payouts to investors are not reinvested into the capital pool. This assumption simplifies the model, as it implies homogeneous capital dynamics. This treatment of cash payouts is typical of asset-management contracts used by private-equity partnerships.

We assume that $\rho_{a}=\epsilon_{a}+\epsilon_{c}$ and $\rho_{b}=\epsilon_{b}+\epsilon_{c}$, where the market-specific compound-Poisson processes $\epsilon_{a}$ and $\epsilon_{b}$ are independent and have the same distribution. The independent component $\epsilon_{c}$ is common to the two markets. This symmetry simplifies the calculation of an equilibrium and has the further illustrative advantage that any differences in the conditional expected returns in the two markets are due solely to differences in the capital levels of the markets. We briefly discuss the asymmetric case in Section 5 .

If there were no capital-market frictions, investors would instantly move capital between the markets so as to obtain the higher dividend rate, and in doing so would equate the dividend rates $\pi\left(X_{a t}\right)$ and $\pi\left(X_{b t}\right)$, and thereby equate $X_{a t}$ and $X_{b t}$ at all times. Indeed, given the symmetrically distributed returns of the two markets, investors would do so even if they were risk-averse, provided that they have no other hedging motives.

Frictions in the movement of capital may, however, lead to unequal levels of capital in the two markets, and therefore unequal mean rates of return. If, for example, $X_{a t}<X_{b t}$, then the conditional excess mean rate of return of the risky asset in market $a$ exceeds that in market $b$ by $\pi\left(X_{a t}\right)-\pi\left(X_{b t}\right)$, despite the identical idiosyncratic and systematic risks of the two assets. Whichever market has "too much capital" receives the lower risk premium.

An investor chooses how to deploy reinvested capital between the two markets, subject to the available trading technology. Letting $C_{t}$ denote the net cumulative amount of capital moved by a particular investor from market $a$ into market $b$ through time $t$, this investor's capital levels, $W_{a t}^{C}$ in market $a$ and $W_{b t}^{C}$ in market $b$, thus satisfy

$$
d W_{a t}^{C}=W_{a t-}^{C} d \rho_{a t}-d C_{t}
$$

and

$$
d W_{b t}^{C}=W_{b t-}^{C} d \rho_{b t}+d C_{t},
$$

where $W_{i t-}^{C}=\lim _{s \uparrow t} W_{i t}^{C}$ is the level of capital "just before" time $t$. Capital can be moved only when in contact with an intermediary, as will be explained. A model for a proportional intermediation-fee process $K$ will be determined in equilibrium. An investor is infinitely lived, and thus has a utility of

$$
E\left(\int_{0}^{\infty} e^{-r t}\left(\left[W_{a t}^{C} \pi\left(X_{a t}\right)+W_{b t}^{C} \pi\left(X_{b t}\right)\right] d t-K_{t-} d|C|_{t}\right)\right),
$$


where $|C|_{t}$ denotes the total variation of $C$ up to time $t$. For simplicity, we have assumed that transactions costs are paid directly by investors, and not deducted from the capital moved from market to market.

Because there is a continuum of investors, each takes as given the total capital processes $X_{a}$ and $X_{b}$ of the respective markets.

Intermediaries contact investors in order to profit from fees for moving their capital from one market to another. The intermediation fee is a fraction $q$ of the gain in present value to an investor associated with redeploying the investor's capital. For now, we take this bargaining power $q$ as an exogenous parameter. We endogenize $q$ in Section 4 for the case of multiple intermediaries.

Conditional on the intensity process $\lambda$ for contacts of investors by intermediaries, investors are contacted pairwise independently ${ }^{3}$ at the conditional mean rate $\lambda_{t}$. An intermediary's rate of cost for applying contact intensity $\lambda_{t}$ is $c \lambda_{t}$, for some technological cost coefficient $c \geq 0$. For example, doubling the expected rate at which investors are contacted costs the intermediary twice as much. ${ }^{4}$ The maximum feasible contact intensity of the market is some constant $\bar{\lambda}>0$.

The utility of an intermediary is the expected present value of intermediation fees net of intermediation costs. The intermediary maximizes this utility with respect to the choice of intensity process $\lambda$. In the next section, we formalize this maximization problem in the context of a monopolistic intermediary, in a Markov equilibrium setting. Later, we show how the solution of the monopolistic case can be exploited to more easily address the case of oligopolistic intermediaries.

In the final section, we explain that our results extend easily to handle the random arrival and departure of capital suppliers, and to allow capital suppliers to use their own personal technologies for trading, in addition to obtaining intermediation services.

\section{THE MONOPOLISTIC CASE}

We begin with the case of a monopolistic intermediary. We restrict attention to the illustrative example of an insurance market in which each loss event affects only one of the two markets and results in a total loss of capital $(\bar{\nu}=1)$. Appendices treat more general cases, including partial recovery, loss events that can affect both markets simultaneously, as well as proportional losses and gains that are based on Brownian motion.

\footnotetext{
${ }^{3}$ That is, conditional on the path $\left\{\lambda_{t}: t \geq 0\right\}$ of the intermediation intensity process, the times of contacts of any distinct pair of investors, $i$ and $j$, are the event times of independent Poisson processes $N_{i}$ and $N_{j}$ with the common time-varying intensity process $\lambda$.

${ }^{4}$ This can be viewed as a contact technology in which the intermediary adjusts a "broadcast" intensity, for example adjusting the rate of purchase of advertisements or other forms of marketwide intermediation efforts. This differs from a model in which, for example, contacting twice as many individuals at a given intensity costs twice as much.
} 


\subsection{Equilibrium}

We will define and characterize equilibria in which the intermediation intensity is of the symmetric Markov form $\lambda_{t}=\Lambda\left(X_{t}, Y_{t}\right)$, for some measurable policy function $\Lambda: \mathbb{R}_{+}^{2} \rightarrow[0, \bar{\lambda}]$, where

$$
\begin{aligned}
& X_{t}=\max \left(X_{a t}, X_{b t}\right), \\
& Y_{t}=\min \left(X_{a t}, X_{b t}\right) .
\end{aligned}
$$

In equilibrium, at any time, only investors in that market with greater capital agree to have any of their capital moved to the other market. Because an investor has linear preferences, it is optimal when contacted to move either no capital or all capital to the other market. ${ }^{5}$

In a manner similar to that of Weill (2007), the exact law of large numbers allows us to calculate the aggregate rate of movement of capital. We let $W_{a j}(t)$ and $W_{b j}(t)$ denote the levels of capital in markets $a$ and $b$, respectively, of investor $j$ at time $t$. Letting $m(\cdot)$ denote the non-atomic measure over the space of investors, the total rate at which capital is moved from market $a$ to market $b$ is almost surely ${ }^{6}$

$$
\begin{aligned}
\int \lambda_{t} 1_{\left\{X_{a t}>X_{b t}\right\}} W_{a j}(t) d m(j) & =\lambda_{t} 1_{\left\{X_{a t}>X_{b t}\right\}} \int W_{a j}(t) d m(j) \\
& =\lambda_{t} 1_{\left\{X_{a t}>X_{b t}\right\}} X_{a t} .
\end{aligned}
$$

Likewise, the rate at which capital moves from market $b$ to market $a$ is $\lambda_{t} 1_{\left\{X_{b t}>X_{a t}\right\}} X_{b t}$.

The continuation value of an investor per unit of capital in the market with excess capital can be represented as $G\left(X_{t}, Y_{t}\right)$, for some $G: \mathbb{R}_{+}^{2} \rightarrow[0, \infty)$, and likewise for the present value $H\left(X_{t}, Y_{t}\right)$ of each unit of capital in the undercapitalized market.

These values, defined from primitive stochastic processes in Appendix A, include the effects of future movements of capital to a market that is undercapitalized and, once that market becomes over-capitalized, back to the other market, and so on. Assuming differentiability, which we will verify in equilibrium, Itô's formula implies that $G$ and $H$ are characterized as solutions to the

\footnotetext{
${ }^{5}$ If he or she has any capital in the market with more total capital, then all of this investor's capital will be moved, provided the proportional transaction-costs process $K$ is not too large, and this is the case in any equilibrium for our model, as we shall see once the model is completely specified. Thus, although we allow that a given supplier of capital may initially have nonzero capital in both markets, all of his or her invested capital will optimally be held in just one of the two markets at any time after the first time of contact with an intermediary.

${ }^{6}$ Sun (2006) showed that the probability space, the agent space, and the measurable subsets of their product can be constructed so as to satisfy the exact law of large numbers. With this, the total quantity of contacts of agents by intermediaries up to time $t$ is $\int N_{i t} d m(i)=\int_{0}^{t} \lambda_{s} d s$ almost surely.
} 
coupled equations

$$
\begin{aligned}
r G(x, y)= & \pi(x)-G_{x}(x, y) x \Lambda(x, y)+G_{y}(x, y) x \Lambda(x, y) \\
& +(1-q) \Lambda(x, y)(H(x, y)-G(x, y)) \\
& -\eta G(x, y)+\eta(G(x, 0)-G(x, y)), \\
r H(x, y)= & \pi(y)-H_{x}(x, y) x \Lambda(x, y)+H_{y}(x, y) x \Lambda(x, y) \\
& +\eta(G(y, 0)-H(x, y))-\eta H(x, y),
\end{aligned}
$$

where subscripts denote partial derivatives. The first of these equations states that in the over-capitalized market the rate of loss in value due to time preference, $r G(x, y)$, is equal to the total expected rate of net profit to investment in that market. That rate of expected profit includes, first of all, the dividend payout rate $\pi(x)$. The next two terms are the rates of change of $G\left(X_{t}, Y_{t}\right)$ due to intermediated flows of capital out of the over-capitalized market and into the under-capitalized market, respectively. The following term is the expected rate of gain $(1-q) \Lambda(x, y)(H(x, y)-G(x, y))$, net of intermediation fees, associated with the chance to switch to the higher-premium under-capitalized market. The final two terms reflect the expected rate of impact of loss events. As the basic version of the model assumes no recovery value at these events, $\eta G(x, y)$ is the expected loss in value due to the occurrence of these loss events in the investor's market. The final term $\eta(G(x, 0)-G(x, y))$ is the expected gain to the investor associated with a loss event in the other market. The second equation, for the total rate of investment return while in the under-capitalized market, is similarly explained.

Fixing an intermediation policy $\Lambda$, the gain in present value per unit of redeployed capital at time $t$, before the associated fee, is

$$
F^{\Lambda}\left(X_{t}, Y_{t}\right)=H\left(X_{t}, Y_{t}\right)-G\left(X_{t}, Y_{t}\right) .
$$

Thus, at bargaining power $q$, the intermediary's fee per unit of redeployed capital is $q F^{\Lambda}\left(X_{t}, Y_{t}\right)$.

If forced to accept the fees associated with a conjectured intermediation policy $\Gamma$, a monopolistic intermediary's optimal value for beginning with capital levels $x$ and $y$ in the respective markets is

$$
V(x, y)=\sup _{\Lambda} E\left(\int_{0}^{\infty} e^{-r t} \Lambda\left(X_{t}, Y_{t}\right)\left(X_{t} q F^{\Gamma}\left(X_{t}, Y_{t}\right)-c\right) d t\right) .
$$

If a policy $\Lambda$ that solves this problem is the same as conjectured policy $\Gamma$, then we say that $\Lambda$ is an equilibrium. Thus, in equilibrium, fees are based on consistent conjectures by investors of the monopolist's future intermediation intensity process. 
We assume, and later verify, that the intermediary's equilibrium initial value $V(x, y)$ is finite and differentiable. The associated Hamilton-Jacobi-Bellman (HJB) equation, for fees determined by a conjectured intermediation policy $\Gamma$, is

$$
0=\sup _{\ell \in[0, \bar{\lambda}]}\{-r V(x, y)+\mathcal{U}(V, x, y, \ell, \Gamma)\},
$$

where, by Itô's formula,

$$
\begin{aligned}
\mathcal{U}(V, x, y, \ell, \Gamma)= & -V_{x}(x, y) \ell x+V_{y}(x, y) \ell x \\
& +\eta[V(y, 0)+V(x, 0)-2 V(x, y)] \\
& +\ell\left(x q F^{\Gamma}(x, y)-c\right) .
\end{aligned}
$$

PROPOSITION 1-HJB Equation: Given an assumed intermediation policy $\Gamma$, suppose that $\hat{V}$ is a bounded differentiable function satisfying the HJB equation (4). Then $\hat{V}$ is the value function $V$ of the optimization problem (3). Any measurable policy $(x, y) \mapsto \Lambda(x, y)$ which, for each $(x, y)$, attains the supremum (4) is an optimal policy.

The proof, given in Appendix E.2, is by a traditional martingale verification argument.

From the HJB equation, it is optimal for a monopolistic intermediary to search at maximal intensity for opportunities to move capital whenever it is strictly beneficial to search at all, and this is precisely when

$$
q F^{\Lambda}\left(X_{t}, Y_{t}\right)-\left[V_{x}\left(X_{t}, Y_{t}\right)-V_{y}\left(X_{t}, Y_{t}\right)\right]>\frac{c}{X_{t}} .
$$

The left-hand side is the fee per unit of capital moved, net of the associated marginal loss in present value of future intermediation fees. This loss in future fees is caused by the associated reduction in heterogeneity of capital levels across the two markets, which always lowers the gain to investors of shifting their capital. The right-hand side of (5) is the cost of search per unit of capital that can be attracted.

To obtain the simplification associated with homogeneity, ${ }^{7}$ we suppose that the inverse demand function $\pi(\cdot)$ is of the form $k_{0}+k / x$ for positive constants $k_{0}$ and $k$. As explained in the insurance setting of Appendix D, this can be arranged by suitable assumptions on the cross-sectional distribution of hedgers' aversions to loss risk. Capital is therefore optimally reinvested locally, absent an opportunity to move capital to a different market, so long as the mean rate

\footnotetext{
${ }^{7}$ In Appendix A, some results are shown for the more general case $\pi(x)=k_{0}+k x^{-\gamma}$ for where $\gamma$ is any positive constant.
} 
of return to investment exceeds the discount rate. Because investors will only participate in local investment at a nonnegative risk premium, we have

$$
\pi(x)-\eta-r=k_{0}-\eta-r-\frac{k}{x} \geq 0 .
$$

Because $x$ is unbounded, it must therefore be the case that $k_{0} \geq r+\eta$. Because the constant $k_{0}$ is common to the two markets, it has no effect on benefits to investors of moving their capital. Our analysis of the equilibrium therefore proceeds without loss of generality by ignoring $k_{0}$ (treating it as though equal to zero) until further notice.

Because the intermediary has linear time-additive preferences and because of the homogeneity of $\pi$, it is natural to look for equilibria for which the ratio $Z_{t}=X_{t} / Y_{t}$ of total capital in the over-capitalized market to total capital in the under-capitalized market determines the optimal intermediation intensity, and we focus on such equilibria from now on. A loss event causes the capital ratio $X_{t} / Y_{t}$ to jump to $+\infty$. While we allow this formally, the analysis can be done similarly in terms of the ratio $Y_{t} / X_{t}$, which remains in $[0,1]$ almost surely, and our results apply with only notational changes. ${ }^{8}$

The homogeneity of the payout-rate function $\pi$ and policy $\Lambda$ implies that $H$ and $G$ are homogeneous of degree -1 . As a result, $G(z, 0)=g_{0} k z^{-1}$ for some positive constant $g_{0}$ to be determined. Letting $f(z)=F^{\Lambda}(z, 1) / k$ and $L(z)=\Lambda(z, 1)$, homogeneity of $F^{\Lambda}$ and direct calculation from (1) and (2) imply that $f$ solves the ordinary differential equation

$$
\begin{aligned}
0= & -r f(z)+\left(1-z^{-1}\right)-z L(z) f^{\prime}(z)+\left(-f(z)-z f^{\prime}(z)\right) L(z) z \\
& -(1-q) f(z) L(z)+\eta\left[g_{0}\left(1-z^{-1}\right)-2 f(z)\right] .
\end{aligned}
$$

The relevant boundary condition is $f(1)=0$, corresponding to no gain from switching when the two markets have the same capital levels. The dynamic equation for the homogenized gain from switching can be broken down as follows. The first term is a standard discounting term. The second term is the premium differential across markets. The third and fourth terms capture the

\footnotetext{
${ }^{8}$ Provided the initial conditions include a strictly positive amount of capital in at least one market, the probability that $X_{t}$ and $Y_{t}$ ever reach zero at the same time is 0 . The partial-recovery case that we analyze in Appendix $\mathrm{H}$ has strictly positive capital levels in both markets at all times after time zero, given a strictly positive level of capital in at least one of the markets at time zero. In that context, the assumption that loss events strike only one of the two markets at a time is without loss of generality because any common jump component would have no effect on the ratio of $X$ to $Y$. The sole exception is a case of common jumps with a jump-size distribution that supports -1 , in which case there is a nonzero probability that $X_{t}$ and $Y_{t}$ can be zero simultaneously. For the same reason, it is without loss of generality when characterizing equilibria that the return processes $\rho_{a}$ and $\rho_{b}$ have no drift, that is, a component that is linear in $t$. Any common Brownian component is likewise irrelevant to optimal intermediation behavior.
} 
impact of the switching activity on market heterogeneity. Because we consider the homogenized version of the equation, this impact is twofold (any capital increase in the small market must be renormalized to 1). The fifth term captures investors' gain from the switching activity, while the last term takes into account capital losses on both markets. Our next result is that the switching gain $f(z)$ is strictly positive whenever capital levels are unequal.

PROPOSITION 2: Given any intermediation policy $\Lambda, f(z)$ is strictly positive for $z>1$. That is, given any $\Lambda$, investors in the over-capitalized market optimally accept the offer to move all of their capital out of the over-capitalized market whenever given the opportunity.

Taking $F^{A}$ as given, the optimal present value $V$ of intermediation profits is homogeneous of degree 0 , that is, $V(x, y)=V(x / y, 1)$ for $y>0$. In particular, the policy $\Lambda$ achieving the supremum of the HJB equation (4) must also be homogeneous of degree 0 ; that is, $\Lambda(x, y)=L(x / y)$ for some $L(\cdot)$. Because the switching-gain function $f$ depends on the policy function $L$, the determination of equilibrium is reduced to a fixed-point problem: Find a pair $(f, L)$ such that: (i) given $f$, the policy $L$ is optimal, and (ii) given $L$, the marginal gain function $f$ is that determined by $L$ through (6).

In Appendix A.3 (Proposition 12), we show that any equilibrium must be of the "bang-bang" form:

$$
\begin{aligned}
\Lambda(x, y) & =0, \quad x<T y, \\
& =\bar{\lambda}, \quad x \geq T y,
\end{aligned}
$$

for some trigger ratio $T \geq 1$ of the capital level in the over-capitalized market to the capital level in the under-capitalized market. This is intuitive. Because the HJB equation is linear with respect to the intensity chosen by the intermediary, we anticipate the optimality of switching from minimal to maximal intensity whenever there is sufficient marginal gain from moving capital from one market to the other. This occurs when the levels of capital in the two markets are sufficiently different. Our problem is reduced to finding an optimal trigger ratio $T$, which then completely determines equilibrium behavior. ${ }^{9}$

The differential equation (6) for $f$ now reduces to

$$
\begin{aligned}
& (r+2 \eta+\bar{\lambda}[(1-q)+z]) f(z)+\bar{\lambda}(1+z) z f^{\prime}(z) \\
& \quad=\left(1+\eta g_{0}\right)\left(1-\frac{1}{z}\right), \quad z \geq T,
\end{aligned}
$$

\footnotetext{
${ }^{9}$ If the intermediary could fully commit to a policy, it might be optimal for him to reduce mobility strictly below full capacity.
} 
and

$$
(r+2 \eta) f(z)=\left(1+\eta g_{0}\right)\left(1-\frac{1}{z}\right), \quad z \in[1, T] .
$$

For $z \in[1, T]$, the solution is trivial:

$$
f(z)=\frac{1+\eta g_{0}}{r+2 \eta}\left(1-\frac{1}{z}\right) .
$$

In particular, we verify that $f(1)=0$, consistent with the observation that the net present value of moving capital from one market to the other is 0 when the levels of capital in the two markets are the same.

We can rewrite (7) as

$$
(a+z) f(z)+z(1+z) f^{\prime}(z)=\left(1-\frac{1}{z}\right) b, \quad z \geq T,
$$

where $a=(r+2 \eta+(1-q) \bar{\lambda}) / \bar{\lambda}$ and $b=\left(1+\eta g_{0}\right) / \bar{\lambda}$.

Letting $v(z)=V(z, 1) / k$, the HJB equation reduces to

$$
\begin{aligned}
0= & \sup _{\ell \in[0, \bar{\lambda}]}\left\{-r v(z)-\ell z v^{\prime}(z)-\ell z^{2} v^{\prime}(z)\right. \\
& \left.+2 \eta\left[v_{0}-v(z)\right]+\left(q z f(z)-\frac{c}{k}\right) \ell\right\},
\end{aligned}
$$

where $v_{0}=V(y, 0) / k=V(x, 0) / k$. Therefore,

$$
v(z)=v_{1}, \quad z \in[1, T]
$$

where

$$
v_{1}=\frac{2 \eta}{r+2 \eta} v_{0}<v_{0}
$$

and

$$
\kappa v(z)+v^{\prime}(z) z(1+z)=d+q z f(z), \quad z \geq T,
$$

where $\kappa=(r+2 \eta) / \bar{\lambda}$ and

$$
d=\frac{2 \eta v_{0}}{\bar{\lambda}}-\frac{c}{k}
$$

Appendix A.2 contains a proof of the following monotonicity and regularity of $v(\cdot)$. Monotonicity of the value $v(z)$ in the capital heterogeneity measure $z$ is not an obvious result, in particular because the switching gain $f(z)$ is 
not, in general, monotonic. That is, fixing the capital level $y=1$ in the market with less capital, the marginal gain $f(x)$ from switching capital from the overcapitalized market to the under-capitalized market need not be monotone in $x$ even though the increase in payout rate $\pi(y)-\pi(x)$ is strictly monotone in $x$. This is the case because, as $x$ gets large, both $g(x)$ and $h(x) \equiv H(x, 1) / k$ go to zero, and so must therefore $f(x)=h(x)-g(x)$ go to zero. Intuitively, as $x$ gets large, the global amount of capital is large, and although it can be intermediated from one market to another, the value of being a capitalist is not attractive when there is "too much" capital relative to the demand by hedgers to lay off risk.

The intuition for monotonicity of $v(z)$, however, is that, for any assumed trigger ratio $T$, optimal or not, the total rate of activated intermediation fees $q \bar{\lambda} z f(z)$, per unit of capital in the over-capitalized market, is not relevant on $[0, T]$ by definition of $T$, and is strictly increasing in $z$ above $T$. In particular, even though $f(z)$ need not be monotone in $z, z f(z)$ is monotone in $z$, as shown in Appendix A.2. Intuitively, $z f(z)$ is the aggregate trade surplus generated by the intermediary's activity, and that surplus is increasing in market heterogeneity.

PROPOSITION 3-Value Function Monotonicity: For any trigger capital ratio $T$, the solution $v$ of (11)-(14) is bounded, increasing, and strictly increasing on $[T, \infty)$.

The smooth-pasting condition $v^{\prime}(T)=0$ is equivalent to

$$
q T f(T)=\frac{c}{k}
$$

and implies the trigger capital ratio

$$
T=1+\frac{c(r+2 \eta)}{\left(1+\eta g_{0}\right) q k} .
$$

To identify the constant $g_{0}$, we use a conservation equation: The sum of the value functions of all investors and of the intermediary must be equal to the present value of all cash dividend payments net of the search costs incurred by the intermediary. After calculations shown in Appendix A.1, this conservation principle is equivalent to

$$
k g_{0}=\frac{2}{r}-\frac{c \bar{\lambda}}{r}\left(1-e^{-(2 \eta+r) a(T)}\right)-k v_{0},
$$

where $a(T)=\log (1+1 / T) / \bar{\lambda}$.

A proof of the following result guaranteeing the existence and uniqueness of a trigger strategy is found in Appendices A.4 (existence) and A.5 (uniqueness). 
PROPOSITION 4-Existence and Uniqueness: There exists a unique trigger capitalization ratio T satisfying (17), (7), (8), and (16).

An iterative algorithm for computing the equilibrium is presented in Appendix F, whose steps exploit the previous equations as follows: starting from some initial level of $v_{0}$, Equations (16) and (17) are used to determine $g_{0}$ and the threshold $T$. Using these values, the ordinary differential equation (14) is used to determine a new value of $v_{0}$ as the limit of $v(z)$ as $z$ goes to infinity, concluding the first iteration of the algorithm.

This analysis leads to the following characterization of equilibrium, which includes the result that, in the absence of search costs, the intermediary does not exploit his position to restrict movement of capital, but rather provides maximal intermediation, nevertheless generating fee income from his or her imperfect ability to instantaneously move capital from one market to the other due to the upper bound $\bar{\lambda}$ on contact intensity. As $\bar{\lambda}$ becomes large, the capital levels will be nearly equated across the two markets at all times, as in a completely frictionless market, and in the limit there would be no intermediation rents.

PROPOSITION 5: Suppose that the payout-rate function $\pi$ is of the form $\pi(x)=$ $k_{0}+k / x$. Then there exists a unique equilibrium. In equilibrium, there is no intermediation $\left(\lambda_{t}=0\right)$ whenever the ratio of capital levels in the two markets is between $1 / T$ and $T$, for a uniquely determined capital-ratio trigger $T$. Otherwise, intermediation is at full capacity $\left(\lambda_{t}=\bar{\lambda}\right)$. The trigger ratio $T$ is given by (16), where the constant $g_{0}$ is given by (17). If there is no intermediation cost $(c=0)$, then the intermediary always works at full capacity (i.e., $T=1)$.

\subsection{How Intermediation Depends on Market Parameters}

We turn to comparative statics, focusing on the behavior of the threshold capital ratio $T$. A higher trigger ratio $T$ corresponds to less intermediation, because the intermediary waits until $X_{t} / Y_{t}$ exceeds $T$ before becoming maximally active. We therefore define capital mobility to be increasing in a parameter whenever the equilibrium threshold $T$ is decreasing in that parameter. We show that these comparative statics carry over to the oligopolistic case.

PROPOSITION 6-Comparative Statics for $c, k, \eta$, and $r$ : Capital mobility is decreasing in the intermediation cost coefficient $c$, increasing in the payout-rate coefficient $k$, and decreasing in the discount rate $r$. Fixing the dividend payout rate function $\pi(\cdot)$, capital mobility is decreasing in the loss-event intensity $\eta$.

A proof is provided in Appendix G. It is intuitive that increasing the costs of intermediation, represented by $c$, reduces the amount of intermediation provided in equilibrium. Once the trigger $T$ is chosen, the costs of search intensity 
are borne entirely by the intermediary. Other things equal, raising $c$ therefore lowers the desire to search. The coefficients $c$ and $k$ affect the trigger $T$ only through the ratio $c / k$, explaining the comparative static for $k$. Intuitively, multiplying $c$ and $k$ by the same factor amounts to a change of currency unit, which is why only the ratio $c / k$ affects the equilibrium threshold. The comparative statics for $\eta$ and $r$ are more subtle because, for a given trigger ratio $T$, both $\eta$ and $r$ have an effect on the value functions of investors. Equation (16) is the key to understand these comparative statics. A higher after-shock continuation value for investors (i.e., a higher $g_{0}$ ) results in a lower $T$ and thus a higher capital mobility. A higher $r$ has two effects on investors. The direct effect is that it reduces their gain from switching capital, which is the role of $r$ in the numerator of (16). The indirect effect is that, because the present value of gain from switching capital is lower for higher $r$, investors pay lower fees to the intermediary, resulting in a higher $g_{0}$. As we show in our proof, the former effect dominates the latter, so $T$ is decreasing in $r$. One intuition is that the second effect is an indirect consequence of the first, direct effect, so we may expect the net comparative static to follow the first effect. ${ }^{10}$

Our proof likewise shows that $T$ is increasing in $\eta$, holding $\pi$ fixed. Of course, increasing the mean loss frequency $\eta$ would naturally raise the equilibrium loss insurance rate $\pi\left(X_{i t}\right)$, which on its own would tend to increase intermediation (lower $T$ ). To analyze this effect, we write $\pi(x)=k_{0}(\eta)+k(\eta) / x$ to show the dependence of the coefficients $k_{0}(\eta)$ and $k(\eta)$ on the mean loss rate $\eta$. The coefficient $k_{0}(\eta)$ plays no role in intermediation gains. The impact on intermediation intensity of replacing $\eta$ with some $\eta^{\prime}>\eta$ is thus equivalent to the effect of leaving $\pi$ unchanged and replacing the cost coefficient $c$ with $c^{\prime} \leq c k(\eta) / k\left(\eta^{\prime}\right)$. This effect can be small or large, depending on the sensitivity of $k(\eta)$ to $\eta$, reflecting how the elasticity of hedging demand varies with the expected loss frequency. Thus, the overall impact on intermediation intensity of a given increase in the loss-event intensity $\eta$ is to lower intermediation incentives (raise $T$ ) precisely when the impact on $k(\eta)$ is sufficiently small, and otherwise to raise intermediation intensity.

Increasing the bargaining power $q$ of the intermediary increases the fraction of the gains to trade that goes to the intermediary, prompting the intermediary to search for more investor capital to move, thus setting a lower trigger ratio $T$, holding constant the gains to investors for moving capital. Obviously, however, raising $q$ lowers the present value of investors associated with future movements of capital, thus lowering the amount of gain they have to share with the intermediary. The proof in Appendix $G$ of the following result demonstrates that the direct effect dominates the indirect effect on the investors' values, provided that $q$ remains below $1 / 2$.

\footnotetext{
${ }^{10} \mathrm{The}$ techniques used for the comparative statics of discounting draw on those introduced by Quah and Strulovici $(2009,2012)$
} 
PROPOSITION 7-Comparative Statics for $q$ : Capital mobility is increasing in the bargaining power $q$ of the intermediary, for $0<q<0.5$.

The impact on capital mobility of the capacity $\bar{\lambda}$ for search intensity depends on other parameters, and particularly on the discount rate. There are situations in which lowering $\bar{\lambda}$ lowers the trigger ratio $T$, leading the intermediary to work more often, albeit with a lower capacity. We provide examples and some intuition for the fact that, depending on the discount rate $r$, the threshold capital ratio $T$ can either increase or decrease with capacity. We focus on the impact of $\bar{\lambda}$ on the threshold $T$, noting that the level of $\bar{\lambda}$ has also a direct impact on capital mobility, through the rate at which capital moves from one market to another, when it does.

We argue by continuity from the case of $\eta \simeq 0$. Taking $\pi(x)=k_{0}(\eta)+$ $k(\eta) / x$, we can create a family of economies that keep $k(\eta)$ fixed at some $\bar{k}$ as $\eta$ varies near zero by increasing the loss aversion of hedgers. With this, as $\eta$ approaches zero, the equilibrium intermediation policy converges to a policy that moves capital until the threshold $T$ is reached (with no changes in capital levels afterward), so the associated trigger ratio converges to

$$
T=1+\frac{c r}{\bar{k} q},
$$

which is independent of the capacity $\bar{\lambda}$. Moreover, the associated gain functions converge to a gain function $f$ with

$$
f(T)=\frac{1}{r}\left(1-\frac{1}{T}\right) .
$$

Suppose first that agents are patient (have a low discount rate $r$ ). As $\bar{\lambda}$ goes up, capital heterogeneity goes down, hence the value of moving capital is lower. Moreover, a higher-capacity intermediary will more quickly run out of capital to be moved, and thus stop receiving fees earlier. Overall, this implies by continuity that we can construct example economies with small $\eta$ such that, as $\bar{\lambda}$ is reduced and other parameters are held constant, the intermediary receives more fees, and for longer, and hence the value function of investors is lower, resulting in a higher threshold. ${ }^{11}$

Now, we consider the opposite case of nearly myopic investors (high $r$ ). The previous argument breaks down: Investors do not care much about future heterogeneity; they care mainly about the immediate gain from switching, which depends on current heterogeneity. Moreover, the immediate fees are increasing with capacity $\bar{\lambda}$. A higher-capacity intermediary therefore receives higher

\footnotetext{
${ }^{11}$ See Equation (16), which shows that $T$ is decreasing in investors' after-shock continuation value $g_{0}$.
} 
immediate fees, which reduces investors' overall value of switching capital and increases the threshold.

Numerical examples support this intuition. For $q=0.5, c=\bar{k}$, and $r=0.04$, for $\eta$ sufficiently small and $k(\eta)=\bar{k}$ sufficiently insensitive to $\eta$, the capital trigger $T$ decreases with $\bar{\lambda}$ for $0.01<\bar{\lambda}<0.5$. For the same $q$ and $c$ but taking $r=10$, however, the trigger ratio $T$ increases with the intermediation capacity $\bar{\lambda}$, over the same interval.

\section{INTERMEDIARY COMPETITION}

We now solve for equilibria with oligopolistic or perfectly competitive markets for intermediation.

There are two channels through which intermediary competition affects the equilibrium level of intermediation offered by the market. First, an intermediary internalizes the impact of intermediation intensity on the heterogeneity of capital levels across the two markets, and thus the impact on the intermediary's future profits. A given intermediary does not, however, internalize the effect of increasing its intermediation on reducing the profit opportunities of other intermediaries. Through this first channel, increasing the number of intermediaries should therefore weakly increase the total amount of intermediation. In the benchmark case in which a loss event destroys all capital in the affected market, there is nothing to internalize, because the after-shock situation is independent of the pre-shock heterogeneity level, and our upcoming Proposition 8 states that the threshold is independent of the number of intermediaries. In Appendix $\mathrm{J}$, we explain why there is a strict increase in capital mobility from increasing competition if loss events leave some residual capital, because in this case the post-loss heterogeneity depends on the pre-loss heterogeneity.

The second channel by which increasing competition changes capital mobility is as follows. When in contact with an investor, an intermediary considers the ability of the investor to compare the intermediation fee offered with the fees offered by other intermediaries. This plays a role, in an extension of the model that is offered later in this section, in determining the effective bargaining power of the intermediary, and through that channel, has an impact on the profitability of intermediation. We start by taking bargaining power as fixed and then endogenize the fees received by the intermediary. As we shall see, in some cases the second channel can dominate the first, that is, in which an increase in the number of intermediaries lowers capital mobility.

\subsection{Intermediary Competition at Fixed Bargaining Power}

For a given bargaining power $q$, we show that equilibrium trigger policies for the oligopolistic case can be translated directly from the case of monopolistic intermediation through a simple inspection of the associated Hamilton- 
Jacobi-Bellman equations. From this, we also obtain comparative statics directly from those of the monopolistic case.

For the oligopolistic case, we take $n$ identical intermediaries, each with an upper bound $\bar{\lambda} / n$ on intermediation intensity, and with the same proportional cost $c$ of intermediation. The monopolistic case $(n=1)$ is the special case considered in the previous section. Thus, all cases have the same feasible market dynamics and costs.

We consider only Markov time-homogeneous equilibria. Equilibrium incorporates the degree to which intermediaries internalize the impact of their intermediation intensity on the heterogeneity of capital levels across markets. For an oligopolistic equilibrium in trigger strategies, each of the $n$ intermediaries has a reduced value function $v$, with $v(z)=V(z, 1) / k$, that solves the reduced HJB equation, extending the monopolistic version (11):

$$
\begin{aligned}
0= & \sup _{\ell \in[0, \bar{\lambda} / n]}\left\{-r v(z)+\left(-\frac{(n-1)}{n} \bar{\lambda} 1_{\{z \geq T\}}-\ell\right) z v^{\prime}(z)\right. \\
& -\left(\frac{(n-1)}{n} \bar{\lambda} z 1_{\{z \geq T\}}+\ell z\right) z v^{\prime}(z) \\
& \left.+2 \eta\left[v_{0}-v(z)\right]+\left(q z f(z)-\frac{c}{k}\right) \ell\right\},
\end{aligned}
$$

reflecting the presumption by the given intermediary that the $n-1$ other intermediaries have adopted a specific trigger capital ratio $T$. The equilibrium condition is that the same trigger policy is optimal for the given intermediary. Verification of the HJB solution as the value function and of the optimality of the associated candidate policy function is as for the monopolistic case.

Thus, an equilibrium for the $n$-intermediary problem is again given by bangbang control for all intermediaries, each exerting no effort when $Z_{t}<T$ and maximal intermediation intensity $\bar{\lambda} / n$ whenever $Z_{t} \geq T$, for a trigger capital ratio $T$. We show that optimality implies that there is no intermediation at or below the capital ratio $T$ satisfying the smooth-pasting condition $v^{\prime}(T)=0$. This, along with (19), implies that

$$
q T f(T)-\frac{c}{k}=0
$$

From (20), we see that an intermediary's optimization problem in a setting with $n$ intermediaries is equivalent to that of a monopolistic intermediary with maximum intermediation intensity $\bar{\lambda}$. Indeed, for a given threshold $T$, the monopolistic and oligopolistic cases yield the same function $f$ determining proportional intermediation fees, and hence the same smooth-pasting condition (20).

In fact, this is actually the unique equilibrium, even allowing for the possibility of non-trigger strategies! To see this, consider any Markov equilibrium, 
not necessarily of the trigger-ratio form, and let $f$ denote the function determining the associated gain from switching. An intermediary's HJB equation is of the form (19), except that (i) the aggregate of other intermediaries' contact intensities may be almost arbitrary, and (ii) the value functions may vary across intermediaries. Owing, however, to the form of the HJB equation, the indifference condition is nevertheless given by (20), and thus is the same for all intermediaries. This shows that any Markov equilibrium must be symmetric and of the trigger form. ${ }^{12}$ In fact, repeating arguments from the monopolistic case leads to the following proposition.

PROPOSITION 8: With $n$ intermediaries, there is a unique Markov, homogeneous equilibrium. This equilibrium is symmetric and determined by a trigger capital ratio equal to that of a monopolistic intermediary with the oligopolistic maximal contact intensity $\bar{\lambda}$.

When shocks lead to a partial recovery of capital, however, the intermediation trigger capital ratio $T$ is strictly decreasing in the number $n$ of intermediaries, as shown in Appendix J.

\subsection{Endogenous Bargaining Power}

Competition to supply intermediation may also have an impact on an intermediary's share of gains from trade when in contact with an investor. We next consider the implications of market structure for the intermediary bargaining power $q$. With $n>1$ intermediaries, we suppose that some fraction $\psi_{n}$ of investors are "well connected," meaning that as they prepare to move capital from one market to another, they are in simultaneous contact with more than one intermediary. The number of intermediaries with whom a given investor is in contact could also be random, exploiting the law of large numbers, in which case $\psi_{n}$ can be taken to be the probability that an investor, when contacted, is in contact with more than one intermediary. Intuitively, a well-connected investor has more bargaining power than a "captive" investor, one who is in contact with only one intermediary.

When modeling this intuition with a bargaining game, an issue is whether the contacted intermediary is assumed to know whether the investor is in contact with other intermediaries. We take this case. ${ }^{13}$ Another modeling approach

\footnotetext{
${ }^{12}$ The trigger form comes from showing, as in the monopoly case (Lemma 2), that the function $z \mapsto z f(z)$ is increasing.

${ }^{13}$ It would be possible to allow for one-sided information. The fees derived could be obtained as equilibrium outcomes of a bargaining process, although there may be additional equilibria. See, for example, Sutton (1986). For an alternative approach to treating uncertainty about the degree to which an intermediary's customer is in contact with other intermediaries, see Green (2007).
} 
is a multilateral bargaining game with complete information, as in Stole and Zwiebel (1996).

We consider a bargaining procedure à la Rubinstein (1982), in which the investor and a particular intermediary alternate offers. In our continuous-time setting, the times between offer rounds can be treated as arbitrarily small, so the inter-round discount factor can be taken to be 1 . In that case, the investor and intermediary agree immediately to split the surplus according to the Nash bargaining solution. The investor's share depends on his outside option. If the investor is captive, his outside option is simply $G(x, y)$, the value of remaining in the over-capitalized market. Thus, the normalized Nash product associated with a proportional fee of $s$ is

$$
[v(z)+s-v(z)][h(z)-s-g(z)],
$$

which is maximal at $s=f(z) / 2$, corresponding to $q=1 / 2$, meaning an equal splitting of the gains with the intermediary.

For a well-connected investor, the normalized Nash product is

$$
[v(z)+s-v(z)]\left[h(z)-s-g(z)-\left(1-q_{0}\right) f(z)\right],
$$

where $q_{0}$ is the equilibrium proportion of the gain from trade that the investor would pay to another intermediary if this first round of bargaining were to break down. The Nash product is maximized at $s=q_{0} f / 2$, yielding an equilibrium intermediary share of $q=0$, corresponding to the extraction of all surplus by the well-connected investor. ${ }^{14}$

If the number of intermediaries in contact with the investor is known only by the investor, then $q$ is similarly obtained, and depends on the probability that the investor is captive.

Assuming pairwise independence of the connectedness of individual investors, the average of an intermediary's share of gains across the infinite population of investors is almost surely

$$
q(n)=0 \times \psi_{n}+\frac{1}{2}\left(1-\psi_{n}\right)=\frac{1-\psi_{n}}{2} .
$$

In particular, $q(n)$ is decreasing in $n$ if $\psi_{n}$ is increasing in $n$. Obviously, $\psi_{2} \geq$ $\psi_{1}$. Going beyond the case of $n=2$, it is somewhat intuitive that an investor is more likely to be well connected as the number of intermediaries increases. Appendix B briefly outlines a model with this natural feature.

Noting from (21) that $q(n)<1 / 2$, Proposition 7 hints that lowering $q(n)$ reduces an intermediary's incentive to search, all else equal, because, for given

\footnotetext{
${ }^{14}$ Another way to obtain this prediction is to assume that intermediaries connected to a given intermediary post prices and engage in Bertrand competition. We are grateful to a referee for suggesting the alternative of Bertrand competition.
} 
capital dynamics, lowering $q(n)$ reduces intermediation profits, and therefore lowers the marginal benefit of raising intermediation intensity. We will next illustrate the second channel through which oligopolistic intermediation affects capital mobility: By reducing each intermediary's bargaining power, the incentive to intermediate is lowered.

Endogenous bargaining leads to complex dynamics, in which the number of intermediaries actively searching for capital varies over time. To see this, consider a candidate equilibrium in which $n$ intermediaries search at full capacity whenever $z>T$, and no intermediary searches when $z \leq T$. If a single intermediary deviates by searching for capital when $z$ is in a left neighborhood of $T$, then his fee per unit of capital switched is that of a monopolist, not that of the $n$-intermediary case. This increases the value of this deviation. Despite this added complexity, we now show that oligopolistic intermediation may reduce capital mobility.

\subsection{Reduced Capital Mobility With More Intermediaries}

A Markov strategy profile for $n$ intermediaries consists of functions $L_{1}, L_{2}$, $\ldots, L_{n}$ on $[1, \infty)$ into $[0, \bar{\lambda} / n]$. Here, $L_{i}(z)$ denotes the search intensity of intermediary $i$ when the heterogeneity of capital across the two markets is $z=$ $x / y$. The associated aggregate capital mobility is

$$
L(z)=\sum_{i=1}^{n} L_{i}(z) .
$$

To exploit the fee share $q(n)$ derived above, we focus on simple strategies, for which $L_{i}(z)$ is either 0 or $\bar{\lambda} / n$. With this restriction, ${ }^{15}$ we can associate with any strategy profile an increasing sequence $T_{0}, T_{1}, \ldots, T_{J}$ of capital-ratio thresholds with the property that, whenever the capital ratio $Z_{t}$ is in $\left[T_{j}, T_{j+1}\right)$, a particular set $N_{j}$ of intermediaries is active. We let $n_{j}=\left|N_{j}\right|$ denote the number of intermediaries in $N_{j}$.

Using our previous analysis of the oligopolistic case with fixed bargaining power, we say that a profile of simple strategies is a Markov equilibrium if, for all $j$ and $z \in\left[T_{j}, T_{j+1}\right)$,

$$
q\left(n_{j}\right) z f^{L}(z)-\frac{c}{k} \geq 0,
$$

and

$$
q\left(n_{j}+1\right) z f^{L}(z)-\frac{c}{k} \leq 0,
$$

\footnotetext{
${ }^{15}$ Extending the analysis to general Markov strategies would be possible if one computes, for any possible strategy, the expected fee for each intermediary as a function of his search intensity and of the aggregate search intensity.
} 
where $f^{L}(z)$ denotes the marginal gain to an investor from switching to the market with less capital, given an aggregate intensity policy $L$.

The first inequality means that any intermediary in $N_{j}$ contacting investors at capital ratio $z$ does so optimally, given equilibrium fee share $q\left(n_{j}\right)$. The second equation states that any intermediary in $N_{j}+1$ is optimally not contacting at capital ratio $z$, given the equilibrium fee share $q\left(n_{j}+1\right)$ that he would get if he searched.

We let $\bar{T}=\inf \{\bar{z}: L(z)=\bar{\lambda}, z \geq \bar{z}\}$, the smallest level of capital heterogeneity above which intermediaries search at full capacity. We denote by $T_{1}$ the monopolistic threshold. For the result to follow, recall that $\eta$ is the mean arrival rate of loss events and that $\bar{T}$ depends, through $L$, on the particular Markov equilibrium under consideration. In any equilibrium, $z f^{L}(z)$ is strictly increasing in $z$. (For this, see the proof of Proposition 10.) This fact and Equations (22) and (23) imply that when $q(n)$ is decreasing in $n$ (i.e., a more connected investor pays a lower fee), the number of active intermediaries is increasing in $z$ in any equilibrium.

PROPOSITION 9-Monotonicity: Suppose that $q(n)$ is decreasing in $n$. Then, $n_{j}$ is increasing in $j$.

If $q(n)$ is strictly decreasing in $n$, it is possible to prove by a fixed-point argument the existence of a Markov equilibrium, in which, whenever the capital heterogeneity $Z_{t}$ is $\left[T_{k}, T_{k+1}\right)$, precisely the first $k-1$ intermediaries are active, and the remainder are inactive. ${ }^{16}$

The following result applies to all equilibria.

PROPOSITION 10: Suppose that the number $n$ of intermediaries is at least 2. There exists some $\bar{\eta}>0$ such that, for any loss event intensity $\eta \in(0, \bar{\eta})$ and any associated Markov equilibrium trigger capital ratio $T$, we have $T_{1}<\bar{T}$.

This result states that, for sufficiently infrequent loss events, the reduced bargaining power caused by oligopolistic competition reduces the domain of

\footnotetext{
${ }^{16}$ For a sketch of the proof, let $\mathbb{T}$ denote a vector $\left(T_{0}, \ldots, T_{n}\right)$ in $\mathbb{R}^{n+1}$ of capital heterogeneity thresholds, with increasing elements. We let $L^{\mathbb{T}}$ and $f^{\mathbb{T}}$ denote the associated capital-mobility and switching-gain functions. Taking $\mathbb{T}$ as given, a vector of best-response thresholds is uniquely determined by Equations (22) and (23). The best-response function of the respective intermediaries induces a new vector $\mathcal{B}(\mathbb{T})$ of capital heterogeneity thresholds. It can be checked that $\mathcal{B}(\cdot)$ is continuous. For this, we endow $\mathbb{R}^{n+1}$ with the Euclidean topology and the space of switching-gain functions $\left(f^{L}\right)$ with the sup-norm topology. We have continuity of $\mathbb{T} \mapsto f^{\mathbb{T}}$ because of Equations (22) and (23), and because the best-response thresholds depend continuously on $f^{L}$. Moreover, the best-responses preserve threshold monotonicity. Further, the best-response thresholds are uniformly bounded below by $\underline{T}=r c /(k q(n) 2)$ (using that $f^{L}(z) \leq 2 / r$ for all $z$ ), and bounded above by $\bar{T}=c /(k q(1) f(\underline{T}))$, where $f(z)$ is the gain from switching capital when capital moves at full capacity $\bar{\lambda}$ until $\bar{T}=1$, and satisfies $\underline{f}(z) \leq f^{L}(z)$ for all $L$ and $z$. The result follows from Brouwer's theorem.
} 
maximal capital mobility relative to that of the monopolistic case. Our assumption of a sufficiently small mean arrival rate $\eta$ of loss events exploits the fact that intermediation fees are generated from the time of each loss event until capital is sufficiently equalized across the markets. Although there are technical steps in the proof of this proposition, found in Appendix $\mathrm{C}$, the argument relies on a bound on improvements in the present value of intermediation fees as one changes from one market setting to another. A simple way to provide such a bound is thus to control the speed with which new fee-generating loss events occur.

Proposition 10 shows that oligopolistic competition results in less intermediation than achieved by a monopolist, for some range of market heterogeneity. This does not, however, rule out intermediation by oligopolists at capital ratios below the monopolistic trigger level. The next result shows that, provided that loss events are not expected too frequently, oligopolistic and monopolistic settings lead to a cessation of intermediation at approximately the same levels of market heterogeneity.

For any $n$-intermediary Markov equilibrium with aggregate intermediation strategy $L$, let

$$
S_{n}=\inf \{z: L(z)>0\},
$$

the smallest heterogeneity level above which capital is mobile. A proof of the next proposition may be found in Appendix C. We will rely on a sufficiently small loss-event intensity for the same bounding effect explained after the statement of Proposition 10.

PROPOSITION 11: For any $\varepsilon>0$, there exists a strictly positive $\bar{\eta}$ such that, for any mean loss-event rate $\eta \in(0, \bar{\eta})$ and any associated Markov equilibrium with $n$ players, we have $S_{n} \geq T_{1}-\varepsilon$.

Propositions 10 and 11 together show that capital mobility is lower, at any levels of capital, with oligopolistic intermediation than with monopolistic intermediation, provided that loss events are sufficiently infrequent. ${ }^{17}$

\section{DISCUSSION AND CONCLUDING REMARKS}

In a neoclassical model of asset markets, investors continually adjust their portfolios so as to achieve the highest possible mean return for a given type of risk. In equilibrium, an investor bearing a given type of risk is therefore

\footnotetext{
${ }^{17}$ For the last two results, we have held constant the dependence of the dividend rate function $\pi(x)$ on the capital level $x$ as the mean rate $\eta$ of loss events is varied. We have the freedom, however, of varying the population of hedgers as $\eta$ changes, so as to offset the impact of variation of $\eta$ on $\pi(x)$, thereby satisfying the stated comparison between monopolistic and oligopolistic intermediation for each fixed economy.
} 
compensated by a unique associated excess mean rate of return, no matter the asset that carries the risk. In practice, however, investors make portfolio adjustments with delays. In our model, the mobility of capital across different investments is increased through the equilibrium efforts of intermediaries. Our model has several implications for asset-price dynamics:

1. With unexpected changes in the amount of capital that is available to bear the risk represented by an asset, risk premia adjust more severely to capital shocks than in a neoclassical (perfect-mobility) setting, and then revert somewhat over time as capital is redeployed. This time signature, present in essentially any setting with slow moving capital, is dampened to the extent that intermediaries are active. Consider, for example, our simplest setting in which capital levels change only at the times at which all capital in a given asset market is lost. Perfect capital mobility $(c=0, \bar{\lambda}=\infty)$ implies that $X_{a t}=X_{b t}$ for all $t$. A loss event at time $\tau$ in market $a$ would cause half of the capital from market $b$ to move instantly to market $a$, so risk premia in both markets jump up by

$$
\pi\left(X_{a \tau}\right)-\pi\left(X_{a \tau-}\right)=\frac{k}{X_{a \tau-}},
$$

and then remain constant until the next loss event. With imperfect mobility, however, the risk premium in market $a$ would jump immediately to $+\infty$ and then decline at the rate $\bar{\lambda} Z_{t} \frac{k}{X_{a t}}$ until the capital heterogeneity ratio $Z_{t}=$ $X_{b t} / X_{a t}$ drops to $T$ or until another loss event occurs.

2 . The degree to which risk premia vary across assets, after controlling for other determinants of risk premia, is increasing in the degree to which capital is heterogeneously distributed across assets.

3. The speed of reversion of risk premia across assets toward common levels (after adjustment for other determinants of risk premia) is decreasing in the cost of intermediation. Increasing intermediation capacity, however, can either increase or reduce capital mobility, depending on the setting, as explained in Section 3.2.

4. All else equal, increasing the fraction of gross gains from moving capital that accrue to intermediaries increases the speed of adjustment of capital and risk premia.

5. Lowering time discount rates increases the mobility of capital.

6. Increasing the volatility of asset returns, represented in our model by the mean frequency $\eta$ of loss events, can either increase or decrease the mobility of capital through intermediation, depending on the relative magnitudes of the effects of (i) raising neoclassical risk premia (thus increasing the rents available to intermediaries), and (ii) increasing the volatility of capital heterogeneity at a given level of intermediation, which lowers the incentive to intermediate.

7. Increasing the scope for intermediary competition by splitting the market among more intermediaries can increase or decrease the equilibrium provision 
of intermediation, depending on the relative magnitudes of the effects of (i) reducing the concern of an intermediary regarding the impact of its own activity on lowering capital heterogeneity, and (ii) lowering the bargaining power of an intermediary vis à vis its customers because of increased competition with other intermediaries. As the number of intermediaries increases, the former effect raises intermediation incentives, while the latter effect can lower intermediation incentives.

Our introduction uses the example of the market for catastrophe risk reinsurance. Froot and O'Connell (1999), Zanjani (2002), and Born and Viscusi (2006) explained how premia for catastrophe risk insurance typically increase dramatically when insurance and reinsurance firms suffer significant damage claims after natural disasters, such as Hurricane Andrew in 1992. Then, over many months, premia drop toward "soft-market" levels (absent other shocks to the capital of insurers) because the replacement of insurance capital is delayed by institutional barriers to capital raising, including the time spent searching for suitable new investors. According to Enz (2001), premia swing up and down by as much as $50 \%$ over multiyear periods, and are closely linked with changes in the capital levels of insurers, regardless of whether these changes in capital are caused by damage claims or by unexpected returns to the asset portfolios of insurers. From this, we know that the dynamics of insurance premia after a major natural catastrophe are not caused mainly by inference concerning the arrival rate of future such events. We also know that most of the observed price impacts are not caused by inference about losses because major changes over time in insurance premia following shocks to capital levels are highly correlated across all major lines of property insurance covered by the same pools of capital covering catastrophe risk. ${ }^{18}$ These other lines cover, for example, aviation, marine, motor, and proportional property. The link tying premium dynamics across the various lines of insurance is the level of capital commonly available to bear losses. Apparently, these various property-related insurance markets are not segmented from each other by capital immobility. Rather, they are collectively segmented from other types of capital markets. Froot and O'Connell (1999) emphasized the slow speed of capital replacement as the major cause of slow premium adjustments.

That there is scope for intermediaries to mobilize dormant capital is apparent from a significant body of evidence that, when left on their own, many individual investors adjust their portfolios remarkably infrequently. For example, Ameriks and Zeldes (2004) reported that, over a 10 -year period, $44 \%$ of investors in their sample made no changes to their portfolio allocations, and that an additional $17 \%$ of these investors made a single reallocation during this period. Mitchell, Mottola, Utkus, and Yamaguchi (2006) found that, of 1.2 million U.S. employees covered by over 1,500 401(k) investment plans, approximately $80 \%$ initiated no trades over a two-year period, while an additional

\footnotetext{
${ }^{18}$ See, for example, Enz (2001, p. 5, Figure 1).
} 
$10 \%$ made only a single trade. ${ }^{19}$ Based on our theoretical results, one presumes that investor inattention is more evident in the data when the cost of contacting individuals and deploying their capital is large relative to the potential associated intermediation profits. For example, high-net-worth individual investors and institutional investors are likely to receive more attention from intermediaries because of the amounts of capital they can deploy and the associated higher total intermediation fees, than are most of the smaller investors whose inattention is documented in this literature. This is consistent with evidence provided by Bilias, Georgarakos, and Haliassos (2010) and Feldhütter (2009). Further, variation across investors in financial sophistication (not captured in our model) may lead to a negative correlation between the cost of achieving a given level of contact intensity and the level of deployable capital. In our model, intermediaries cannot differentiate among subclasses of investors.

Delays in processing information for purposes of investment decisions are also in evidence from "price momentum" following fundamental news, as documented empirically by Chan (2003), Engelberg, Reed, and Ringgenberg (2012), Dellavigna and Pollet (2009), and Cohen and Lou (2012), among others. Given that most financial intermediaries are themselves likely to receive and process fundamental news quickly relative to the time for price reactions documented in this literature, one presumes that there are limits on the average speed with which they can attract potential investors to such investment opportunities. This inference is also consistent with numerous examples of slow price adjustments to supply shocks in equity markets, including those of Holthausen, Leftwich, and Mayers (1990), Scholes (1972), Coval and Stafford (2007), Andrade, Chang, and Seasholes (2008), Kulak (2008); with respect to supply shocks caused by index recompositions, see Shleifer (1986), Harris and Gurel (1986), Kaul, Mehrotra, and Morck (2000), Chen, Noronha, and Singhal (2004), and Greenwood (2005); and with respect to the expiration of commodity futures contracts, see Mou (2011).

In corporate bond markets, which are not traded on a central exchange, one observes large price drops and delayed price recovery in connection with major downgrades or defaults, as described by Hradsky and Long (1989) and Chen, Lookman, and Schürhoff (2008), when certain classes of investors have an incentive or a contractual requirement to sell their holdings. Mitchell, Pedersen, and Pulvino (2007) documented the effect on convertible bond hedge funds of large capital redemptions in 2005. Convertible bond prices dropped and rebounded over several months. A similar drop-and-rebound pattern was observed in connection with the LTCM collapse in 1998. Newman and Rierson (2003) showed that large issuances of European Telecom bonds during 19992002 temporarily raised credit spreads throughout the sector, evidence that it takes time for intermediaries to locate long-term investors.

\footnotetext{
${ }^{19}$ For further evidence on the slowness of individual portfolio adjustments, see Lusardi (1999, 2003), Brunnermeier and Nagel (2008), and Bilias, Georgarakos, and Haliassos (2010).
} 
In these examples, the time pattern of returns or prices after a supply or demand shock reveals that the friction at work is not merely a transaction cost for trade. If that were the nature of the friction, then all investors would immediately adjust their portfolios, or not, optimally. The new market price and expected return would be immediately established, and remain constant until the next change in fundamentals. In all of the above examples, however, after the immediate price response, whose magnitude reflects the size of the shock and the supply of immediately available capital, there is a relatively lengthy period of time over which the price reverts in mean toward its new fundamental level. In the meantime, additional shocks can occur, with overlapping consequences. The typical pattern suggests that the initial price response is larger than would occur with perfect capital mobility, and reflects the demand curve of the limited pool of investors that are quickly available to absorb the shock. The speed of adjustment after the initial price response is a reflection of the time that it takes more investors to realign their portfolios in light of the new market conditions, or for the initially responding investors to gather more capital.

In our setting, as in practice, there can be substantial differences in mean returns across assets that are due not only to cross-sectional differences in "fundamental" cash-flow risks, but are also due to unbalanced distributions of capital, relative to a market without intermediation frictions. Empirical "factor" models of asset returns do not often account for factors related to the distribution of ownership of assets, or related to likely changes in the distribution of ownership. Exceptions include the recent work of Coval and Stafford (2007) and Lou (2009), who noted that the conditional mean returns of an equity tend to be lower due to price pressure when mutual funds owning that equity are experiencing liquidation-motivated outflows, and that the conditional mean returns recover as price pressure abates. Similarly, Bartram, Griffin, and $\mathrm{Ng}$ (2010) showed that divergent levels of ownership by national domiciles play a role in equity returns.

In our model, delays in portfolio adjustments are due to the time that it takes for intermediaries to locate suitable investors. This is only an abstraction, which can also proxy for other forms of delay, including time to educate investors about assets with which they have limited familiarity (awareness), time for contracting, and time for investors to dispose of their current positions, which could involve similar delays and price shocks, as suggested by Chaiserote (2008).

Our results extend almost immediately to a model in which, in addition to obtaining the services of an intermediary, each investor also has a personal technology by which opportunities to move capital to the other market arrive at random times, independently across investors, with a constant mean arrival rate. This would cause only minor modifications to the structure and solution of our model. Increasing the mean arrival rates of these alternative capitalshifting opportunities reduces the average degree of imbalance of capital and 
the difference in risk premia between the two markets, and thus reduces the profitability of intermediation.

Our results also apply with minor alteration to an extension of the model that allows for randomly timed exit and entrance of investors. For this, investors would exit at exponentially distributed times that are pairwise independent, and consume their capital at exit. New investors would appear in proportion to the current levels of capital. Any difference between exit and entrance rates would thus be subtracted from the proportional drifts of the capital accumulation processes $X_{a}$ and $X_{b}$.

We could further extend our model so as to treat asymmetric markets. Provided that the local inverse demand function $\pi(\cdot)$ of each market satisfies similar homogeneity assumptions, intermediation would be characterized by two distinct thresholds of capital ratios, one for movement of capital from market $a$ to market $b$, and another for the reverse movement. For example, if returns in market $a$ are riskier than those in market $b$, then, all else equal, capital will be less mobile toward market $a$ than toward market $b$. Asymmetry, for example, would allow a consideration of capital mobility from a low-risk "money market" into a high-risk market such as that for private equity. Many of the qualitative features of our symmetric model, such as the dynamics of capital mobility and the impact of intermediation competition, are anticipated to carry over to asymmetric settings, at least under regularity conditions.

Another natural extension concerns the case of three or more markets. Consider, for example, three symmetric markets differing only in their capital levels, and satisfying our homogeneity conditions. We conjecture that capital will flow exclusively to the highest-premium market, with more mobility from the lowest-premium market than from the mid-premium market.

\section{APPENDIX A: EOUILIBRIUM ANALYSIS}

Here, we provide a stochastic analysis of Markov equilibrium that is more complete and general than that provided in the main text.

Given an intermediation contact intensity process $\lambda$ and initial conditions for capital in each market, we let $X_{i t}^{\lambda}$ denote the total capital in market $i$ at time $t$. Given an associated transaction-cost process $K$, the marginal value to a supplier of one additional unit of capital in market $i$ at time $t$ is

$$
\theta_{i t}^{\lambda}=E\left(\int_{t}^{\infty} e^{-r(s-t)}\left[W_{s} \pi\left(X_{D(s), s}^{\lambda}\right) d s-W_{s-} K_{s-} d N_{s}\right] \mid \mathcal{F}_{t}\right),
$$

where $N_{s}$ is the cumulative number of switches back and forth between the two markets through time $s$ by the holder of this unit of capital, and the market indicator $D(s)$ is $a$ or $b$, depending on whether, at time $s$, the accumulated capital $W_{s}$ is currently located in market $a$ or $b$. This capital thus accumulates according to

$$
d W_{s}=W_{s-} d \rho_{D(s-)}(s),
$$


with initial condition $W_{t}=1$. The market-indicator process $D$ is a marked point process with an initial condition at time $t$ of $D(t)=i$, and with an intensity of jumping from market $i$ to market $j$ at time $s$ of $\lambda_{s} 1_{\left\{X_{i s}^{\lambda}>X_{j s}^{\lambda}\right\}}$. In the equilibrium that we shall describe, the value of switching from market $i$ to market $j$ is strictly positive if and only if $X_{i t}^{\lambda}>X_{j t}^{\lambda}$. The marginal value of moving capital is thus

$$
\phi_{t}^{\lambda}=\max \left(\theta_{a t}^{\lambda}, \theta_{b t}^{\lambda}\right)-\min \left(\theta_{a t}^{\lambda}, \theta_{b t}^{\lambda}\right) .
$$

At each time $t$, intermediaries charge investors some fraction $q \in[0,1]$ of the gain $\phi_{t}^{\lambda}$ from switching each unit of capital. That is, the proportional intermediation fee is $K_{t}^{\lambda}=q \phi_{t}^{\lambda}$.

We restrict $\lambda$ to be a progressively measurable process so that, at each time, the intermediary chooses a contact intensity that depends only on information that is currently available.

A monopolistic intermediary's total rate of fee revenue is $\lambda_{t} \max \left(X_{a t}, X_{b t}\right) \times$ $q \Phi_{t}$, where $\Phi_{t}=\phi_{t}^{\lambda}$ is the gain from switching capital under policy $\lambda$. Given the initial conditions $X_{a 0}^{\lambda}=x_{a}$ and $X_{b 0}^{\lambda}=x_{b}$, and given a gain-from-switching process $\Phi$, the intermediary's utility for a contact intensity process $\lambda$ is

$$
U\left(x_{a}, x_{b}, \Phi, \lambda\right)=E\left(\int_{0}^{\infty} e^{-r t} \lambda_{t}\left[q \Phi_{t} \max \left(X_{a t}^{\lambda}, X_{b t}^{\lambda}\right)-c\right] d t\right) .
$$

We assume that the parameters are such that this utility is finite, which is the case in the equilibria that we analyze. We restrict attention to intermediation policies that depend on the available information only through the current capital levels $\left(X_{a t}, X_{b t}\right)$. The intermediary might otherwise prefer to commit once and for all time to a path-dependent intensity policy that could, at some future time, be dominated by another policy available at that time, given the current capital market conditions at that time.

The inability to commit to an intermediation strategy may, in principle, be overcome by sophisticated punishment threats, as in Ausubel and Deneckere (1989) and Mailath and Samuelson (2006). In such equilibria, if the intermediary deviates, investors would update their beliefs about the intermediary's strategy in a way that harms the intermediary. Such equilibria are based on sophisticated off-equilibrium-path investor beliefs, which are not in the spirit of our assumption that investors are less sophisticated than intermediaries. Another possible justification for our focus on Markov equilibria is the fact that more sophisticated equilibria unravel in finite-horizon models where (possibly state-dependent) stage games have a unique Nash equilibrium.

Given the symmetry of the two markets, it suffices to characterize equilibrium behavior in terms of

$$
\begin{aligned}
& X_{t}=\max \left(X_{a t}, X_{b t}\right), \\
& Y_{t}=\min \left(X_{a t}, X_{b t}\right) .
\end{aligned}
$$


The payoff processes to investments in the "larger" and "smaller" markets are, respectively,

$$
\begin{aligned}
& d \rho_{t}^{X}=1_{\left\{X_{a t}>X_{b t}\right\}} d \rho_{a t}+1_{\left\{X_{a t} \leq X_{b t}\right\}} d \rho_{b t}, \\
& d \rho_{t}^{Y}=1_{\left\{X_{a t} \leq X_{b t}\right\}} d \rho_{a t}+1_{\left\{X_{a t}>X_{b t}\right\}} d \rho_{b t} .
\end{aligned}
$$

From the Lévy property, $\left(\rho^{X}, \rho^{Y}\right)$ has the same joint distribution as the primitive payoff processes $\left(\rho_{a}, \rho_{b}\right)$.

Because we restrict attention to an intermediation intensity process $\lambda$ that depends only on current capital levels, and because of symmetry, we can suppose that $\lambda_{t}=\Lambda\left(X_{t}, Y_{t}\right)$ for some measurable policy function $\Lambda: \mathbb{R}_{+}^{2} \rightarrow[0, \bar{\lambda}]$ with the property that there is a solution to the associated stochastic differential equation

$$
\begin{aligned}
& d X_{t}=-\Lambda\left(X_{t}, Y_{t}\right) X_{t} d t+X_{t} d \rho_{t}^{X}, \\
& d Y_{t}=\Lambda\left(X_{t}, Y_{t}\right) X_{t} d t+Y_{t} d \rho_{t}^{Y} .
\end{aligned}
$$

Letting $\mathcal{L}$ denote the space of intermediation intensity processes of this form, and given an assumed gain-from-switching process $\Phi$, the intermediary solves the problem

$$
\sup _{\lambda \in \mathcal{L}} U(x, y, \Phi, \lambda) .
$$

An equilibrium is a pair $(\lambda, \Phi)$ consisting of an intermediation intensity process $\lambda$ that attains the supremum (27) given $\Phi$, and such that $\Phi_{t}=\phi_{t}^{\lambda}$. This definition includes consistency with the optimality for investors to move their capital, in exchange for the marginal fee determined by $\Phi$, when contacted by the intermediary, and includes consistency between the conjectured and actual dynamics for capital movements and search intensity.

\section{A.1. Nonnegativity of the Gain From Switching $f$}

We now prove Proposition 2, allowing for general $\gamma$. Because the right-hand side of (37) is strictly positive, $f$ or $f^{\prime}$ must be strictly positive. This implies that $f$ cannot cross 0 from above. Hence, $f$ must be strictly positive on some interval of the form $(z, \infty)$, and is nonpositive on $[1, z]$ for some level $z$. It remains to show that $z=1$. Because $f(1)=0$, the intermediary does not search when the markets have equal levels of capital, given that $c>0$. That is, $L(z)$ vanishes on a neighborhood of 1. From (37), this implies that $f$ is positive on that neighborhood, which concludes the proof.

The total-present-value conservation equation is

$$
V(x, y)+x G(x, y)+y H(x, y)=R(x, y)-P_{T}(x, y),
$$


where $R(x, y)$ is the present value of the total future cash flows at rate $X_{t} \pi\left(X_{t}\right)+Y_{t} \pi\left(Y_{t}\right)$, to be divided among the intermediaries and the investors, and $P_{T}(x, y)$ is intermediary's expected discounted search costs over the infinite horizon, given a trigger $T$.

Because $\pi$ is homogeneous of degree -1 , we have $R(x, y)=2 / r$. The search-cost present value $P_{T}(1,0)$ solves

$$
P_{T}(1,0)=p+E\left[e^{-r \tau} P_{T}(1,0)\right],
$$

where $p$ is present value of search costs from time zero to the exponentially distributed time $\tau$ of the next loss event. We now show that, for the case of no recovery at loss event,

$$
P_{T}(1,0)=\frac{c \bar{\lambda}}{r}\left(1-e^{-(2 \eta+r) a(T)}\right),
$$

where $a(T)=\log (1+1 / T) / \bar{\lambda}$.

Starting with $X_{0}=1$ and $Y_{0}=0$, for $t<\tau$ we have

$$
d X_{t}=-\bar{\lambda} X_{t} 1_{\left\{Z_{t}>T\right\}} d t
$$

and

$$
d Y_{t}=\bar{\lambda} X_{t} 1_{\left\{Z_{t}>T\right\}} d t
$$

This yields $X_{t}=e^{-\bar{\lambda} t}$ and $Y_{t}=1-e^{-\bar{\lambda} t}$, for $t<\tau$. The intermediary will stop searching at that time $a(T)$ at which $Z_{a(T)}=T$, so

$$
\frac{e^{-\bar{\lambda} a(T)}}{1-e^{-\bar{\lambda} a(T)}}=T
$$

This yields

$$
a(T)=\frac{1}{\bar{\lambda}} \log \left(\frac{1+T}{T}\right) .
$$

The present value of search costs until the next loss event is

$$
p=E\left[\int_{0}^{\min (a(T), \tau)} e^{-r t} \bar{\lambda} c d t\right]=\frac{\bar{\lambda} c}{r}\left(1-E\left[e^{-r \min (a(T), \tau)}\right]\right) .
$$

Because $\tau$ is exponentially distributed with parameter $2 \eta$,

$$
E\left(e^{-r \tau}\right)=\frac{2 \eta}{2 \eta+r}
$$


and

$$
E\left[e^{-r \min (a(T), \tau)}\right]=\frac{2 \eta+r e^{-r(2 \eta+r) a(T)}}{2 \eta+r} .
$$

Substitution of these into (28) yields the result (29).

\section{A.2. Proof of Proposition 3}

That $v$ is bounded follows from the fact that it is dominated by $2 / r$. The monotonicity result is based on two intermediate lemmas.

First, given the function $f$ determining intermediation fees, let

$$
\varrho(z)=\left(1-z^{-\gamma}\right)\left(\frac{1+\eta g_{0}}{r+2 \eta}\right)-f(z) .
$$

The first term of $\varrho(z)$ is the present value of switching capital to the undercapitalized market if the intermediary arrests intermediation efforts from the point at which the capital ratio $Z_{t}$ is at $z$ until the next loss event occurs, given $g_{0}$. (See (9).) Suppose, in particular, a given reduced policy $L(z)=\Lambda(z, 1)$, and a particular $z$ at which $L(z)=0$. Then $\varrho(z)=0$. As a special case, $\varrho(1)=0$ (which can also be checked directly from the definition of $\varrho$ and the fact that $f(1)=0)$. We note that, since the first term defining $\varrho$ is strictly increasing in $z, \varrho^{\prime}(z)$ must be positive whenever $f^{\prime}(z)$ is negative. Given a policy $L$, we show that $\varrho$ is nonnegative. To see this, we observe that, for $z \geq 1$, (37) can be rewritten as

$$
L(z)\left[((1-q)+z \gamma) f+z(1+z) f^{\prime}\right]=(r+2 \eta) \varrho(z) .
$$

We already know that $\varrho(1)=0$. Since $f$ is positive from Proposition 2, this implies that $f^{\prime}(z)$ is negative whenever $\varrho(z) \leq 0$, and hence that $\varrho^{\prime}>0$ whenever $\varrho \leq 0$. Therefore, $\varrho$ cannot cross 0 from above, which proves our first lemma.

\section{LEMMA 1: For any policy, $\varrho$ is everywhere nonnegative.}

This result is intuitive: other things equal, the expected gain from moving one's capital is larger if the intermediary immediately stops switching capital after that last movement, since the difference between capital levels, and hence between premia, is larger in that case. Lemma 1 has a crucial consequence for the case $\gamma=1$ : The rate at which fees are paid to the intermediary when he searches is strictly increasing in $z$. The more heterogeneous the markets, the higher is the intermediary's immediate profit from switching. Since this rate of fee payment, net of search costs, is $q z f(z)-c$, we must show that $z f(z)$ is strictly increasing in $z$. We can rewrite (30) when $\gamma=1$ as

$$
L(z)(1+z)\left(f(z)+z f^{\prime}(z)\right)=(r+2 \eta) \varrho(z)+q L(z) f(z) .
$$


Since $f$ is positive and $\varrho$ is nonnegative, this implies that $f(z)+z f^{\prime}(z)$ is positive whenever $L(z)>0$, hence that $z f(z)$ is strictly increasing in $z$. On any interval on which $L(z)=0$, we have $f(z)=\left(1+\eta g_{0}\right) /(r+2 \eta)(1-1 / z)$, so $f$ is strictly increasing, and, a fortiori, so is $z f(z)$.

\section{LEMMA 2: For $\gamma=1$ and any policy, the revenue rate $z f(z)$ is strictly increasing in $z$.}

We can now show monotonicity of $v$ for any trigger policy. From (13), $v$ is constant for $z \leq T$. Starting with some capital ratio $Z_{0}=z>T$,

$$
v(z)=E\left[\int_{0}^{\tau} e^{-r t}\left[q f\left(Z_{t}\right) Z_{t}-c\right] 1_{\left\{Z_{t}>T\right\}} d t+e^{-r \tau} v_{0}\right],
$$

where $\tau$ is the time of the next loss event. The function $z \mapsto[q f(z) z-c] 1_{z>T}$ is nondecreasing in $z$ from Lemma 2, and strictly increasing for $z>T$. For $T<z<z^{\prime}$, this implies that $v(z)<v\left(z^{\prime}\right)$ (because the event time $\tau$ has a distribution that does not depend on $z$ or $z^{\prime}$ ). This proves Proposition 3.

\section{A.3. Optimality of a Trigger Policy}

This appendix shows that, for any equilibrium pair $(f, L)$, the reduced policy function $L$ must be a trigger policy. In fact, we show that, for any switching-gain function $f$ that can arise as the result of an admissible intermediation policy, equilibrium or otherwise, the optimal policy must be of the trigger form.

From Appendix E.2, we know that, for a given $f$, any bounded solution of the HJB equation is the value to the intermediary of an optimal policy. We also know that $f$ is continuous (and, in fact, differentiable) from (10). From Lemma 2, we also know that, for any admissible policy, $z f(z)$ must be increasing. Finally, $f$ must be such that the value function $v$ is bounded by $2 / r$. These conditions define what we call "admissibility" of $f$. In particular, these conditions must be satisfied in any equilibrium.

We first show that there exists a solution to the HJB equation that is achieved by a trigger policy. Then we verify that any policy that achieves the value function that solves the HJB equation must be of the trigger form.

For any equilibrium, the function $f$ is bounded, because

$$
f(z)=|h(z)-g(z)| \leq h(z)+g(z) \leq h(z)+z g(z) \leq \frac{2}{r} .
$$

Therefore, given any candidates for the capital trigger ratio $T$ and the constant $v_{1}$, one can integrate the HJB equation $(14)$ on $[T, \infty)$. The smooth-pasting condition is satisfied if $v^{\prime}(T)=0$, and this is equivalent to the condition that $q T f(T)=c$. (For this, see (11).) Given $f$, this uniquely determines $T$, because $T f(T)$ is strictly increasing in $T$, by Lemma 2 . The only difficulty is to show the 
consistency condition $v_{1}=(2 \eta / 2 \eta+r) v_{0}$ (see (13)), where $v_{0}=\lim _{z \rightarrow \infty} v(z)$, noting that $v_{0}$ enters as a coefficient of ordinary differential equation (ODE) (14) (in the constant $d$ ). To show this, we exploit the linearity of the ODE (14). Making the change of variables $u(z)=v(z)-v_{1}$, we have $u(T)=0$. The dynamics of $u$ do not depend on $v_{0}$, in that

$$
u(z)+\alpha z(1+z) u^{\prime}(z)=\beta(z),
$$

where $\beta(z)=\bar{\lambda}(q z f(z)-c) /(r+2 \eta)$ and $\alpha=\bar{\lambda} /(r+2 \eta)>0$ is positive on $(T, \infty)$. Moreover, the limit $u_{\infty}$ is, by construction, equal to $v_{0}-v_{1}$. This allows us to re-express the consistency condition as $u_{\infty}=(r / 2 \eta+r) v_{0}$. Therefore, having integrated $u$ over $[T, \infty)$, one may simply read off the values $v_{0}$ and $v_{1}$. The resulting function $v(t)=u(t)+v_{1}$ solves the initial HJB equation with a $v_{0}$-dependent coefficient, and also satisfies the smooth-pasting condition.

Thus, for any admissible $f$, there is an optimal policy of the trigger form. To conclude, we show that there are no policies solving the HJB equation that are not of the trigger form. This follows from the linearity in $\ell$ of the HJB equation, implying a bang-bang solution, which is strict because indifference is characterized by the equation $q z f(z)=c$, which has a unique solution by Lemma 2. This analysis is summarized as follows.

PROPOSITION 12: Suppose that the payout-rate function $\pi$ is of the form $\pi(x)=k_{0}+k / x$. Then any equilibrium intermediation policy $\Lambda$ corresponds to a trigger capital ratio $T$. That is, $\Lambda(x, y)=\bar{\lambda} 1_{\{x / y>T\}}$.

\section{A.4. Existence of Equilibrium}

So far, we have shown that any equilibrium must be of the trigger form. In this appendix, we show that there exists such an equilibrium. Appendix A.5 shows uniqueness of such equilibria.

For any candidate trigger capital ratio $T$, let $f(z \mid T)$ be the net expected gain from switching capital across markets under the policy with trigger $T$, given current market heterogeneity $z$. We need to show that there exists some $T$ such that $q T f(T \mid T)=c$, that is, such that the intermediary ceases intermediation, given the switching-gain function $f(\cdot)=f(\cdot \mid T)$, exactly when $z=T$. It suffices to show that $T f(T \mid T)$ takes all values between 0 and $\infty$ as $T$ varies from 1 to $\infty$.

Because $z f(z)$ is increasing, Equation (9) implies that

$$
f(z \mid T) \geq \frac{(T-1)}{T(r+2 \eta)}, \quad z \geq T .
$$

This implies that $T f(T \mid T) \geq(T-1) /(r+2 \eta)$. We note that the lower bound grows linearly with $T$. Because $T f(T \mid T)=0$ for $T=1$, we know that $T \mapsto$ $T f(T \mid T)$ goes from 0 to $\infty$ as $T$ goes from 1 to $\infty$. This function is continuous, so there exists some $T^{*}$ such that $T^{*} f\left(T^{*} \mid T^{*}\right)=c / q$. 
Proposition 13: Suppose that the payout-rate function $\pi$ is of the form $\pi(x)=k_{0}+k / x$. Then, there exists an equilibrium with a trigger policy.

\section{A.5. Trigger Uniqueness}

Proof of Proposition 4: Suppose that trigger levels $S$ and $T$, with $S<T$, both satisfy the equations of the proposition. Let $\phi(z)=f^{T}(z)-f^{S}(z)$ denote the difference between the gains from switching capital under policies $S$ and $T$, as a function of $z$. (Throughout, we use superscripts to denote dependence on $S$ or $T$.) From (16), $S<T$ implies that $g_{0}^{S}>g_{0}^{T}$. Optimality of $S$ (respectively, $T$ ) with respect to $f^{S}$ (respectively, $f^{T}$ ) implies that, for any $z$ in $(S, T]$,

$$
q z f^{S}(z)-c-z(1+z)\left(v^{S}\right)^{\prime}(z)>0
$$

and

$$
q z f^{T}(z)-c-z(1+z)\left(v^{T}\right)^{\prime}(z) \leq 0 .
$$

Because $\left(v^{T}\right)^{\prime}(z)=0$ for $z$ in this interval $(S<T]$, while $\left(v^{S}\right)^{\prime}(z) \geq 0$ by Proposition 3, we know that $\phi(T)<0$. Subtracting the version of Equation (7) for $T$ from the version of the same equation for $S$ yields

$$
(a+z) \phi+z(1+z) \phi^{\prime}=\alpha\left(1-\frac{1}{z}\right), \quad z>T,
$$

where

$$
a=\frac{r+2 \eta}{\bar{\lambda}}+(1-q)>0
$$

and

$$
\alpha=\frac{\eta\left(g_{0}^{T}-g_{0}^{S}\right)}{\bar{\lambda}}<0 .
$$

Because $\phi(T)<0$, this ${ }^{20}$ implies that $\phi<0$ for $z>T$, so that $\phi$ is everywhere negative.

By definition, $g_{0}$ is the marginal value of capital held by investors in the overcapitalized market, when $x=1$ and $y=0$ (i.e., when no investor is initially present in the small market). Therefore,

$$
g_{0}=\frac{2}{r}-\Phi_{0},
$$

${ }^{20}$ Indeed, $\phi(z)=0$ implies that $\phi^{\prime}(z)<0$, so $\phi$ cannot cross zero from below. 
where $\Phi_{0}$ is the expected discounted value of all future fees that investors will pay to the intermediary. (Recall that $2 / r$ is the expected discounted stream of dividends paid on both markets.) We have seen that $\phi<0$, that is, $f^{S}(z)>f^{T}(z)$ for all $z>T$. This means that investors pay, for any $z$, more fees with $S$ than with $T$ for $z>T$. Moreover, for $z \in[S, T]$, investors pay fees (which are positive, from Proposition 2) for trigger $S$, whereas they pay nothing for trigger $T$. Therefore, $\Phi_{0}^{S}>\Phi_{0}^{T}$, which implies from (33) that $g_{0}^{S}<g_{0}^{T}$, a contradiction.

Q.E.D.

\section{APPENDIX B: CONNECTEDNESS}

In this appendix, we outline a model with the natural feature that an investor is increasingly likely to be in contact with multiple intermediaries at the point of bargaining as the total number of intermediaries is increased.

Suppose that there is an advertising medium handling intermediary ads. An intermediary's effort corresponds to the probability $p$ that its advertisement will place the intermediary in contact with an investor at the time at which the investor checks the medium. We assume that $p$ is bounded by some capacity constraint $\bar{p}<1$. Each investor, pairwise independently across investors, has some exogenous intensity $\chi$ for the times of monitoring his capital and observing the advertising medium. ${ }^{21}$ This is consistent with the framework of our main model: The intensity of times at which an investor is contacted by at least one intermediary is $\chi \phi_{n}(p)$, where

$$
\phi_{n}(p)=1-(1-p)^{n} .
$$

Then, $\bar{\lambda}=\chi \phi_{n}(\bar{p})$ is the intermediation capacity parameter of the basic model. Assuming that a well-connected investor initiates bargaining with a randomly selected intermediary from among those contacted, each intermediary has maximal contact intensity $\bar{\lambda} / n$. The probability that, when in contact with an intermediary, an investor is in contact with at least two intermediaries is

$$
\psi_{n}(p)=1-(1-p)^{n}-n p(1-p)^{n-1} .
$$

For a fixed $\bar{\phi} \in[0,1]$, let $\bar{p}_{n}$ solve $\phi_{n}\left(\bar{p}_{n}\right)=\bar{\phi}$, so that $\bar{\lambda}$ is independent of $n$, as in our basic model. One may easily check that $\bar{p}_{n}$ is decreasing in $n$. Moreover, using that

$$
\psi_{n}\left(p_{n}\right)=\bar{\phi}-n p_{n}\left(1-p_{n}\right)^{n-1}=\bar{\phi}-\frac{(1-\bar{\phi}) n p_{n}}{1-p_{n}},
$$

\footnotetext{
${ }^{21}$ At such times, the investor observes the medium and plays a bargaining game with advertised intermediaries. If bargaining breaks down, the investor leaves his capital in the large market, until the next monitoring time.
} 
one can show that $\psi_{n}\left(p_{n}\right)$ is increasing in $n .{ }^{22}$ Therefore, keeping constant the flow of investors being contacted at any given time, the average number of intermediaries in contact with any given investor is increasing in $n$. As the number of intermediaries goes to infinity, the probability that investor is well connected is

$$
\lim _{n \rightarrow \infty} \psi_{n}\left(p_{n}\right)=\bar{\phi}+(1-\bar{\phi}) \log (1-\bar{\phi}) .
$$

The second term is negative. This specification can be generalized to an arbitrary number of media, with the same result that $\psi_{n}$ is increasing in $n$.

\section{APPENDIX C: ProOFS OF RESUlTS IN SECTION 4.3}

Proof of Proposition 10: As before, we let $g_{0}^{L}=G(1,0)$, under strategy $L$. For any equilibrium with aggregate mobility $z \mapsto L(z)$ and fee $z \mapsto q(z)$, one can easily modify the proofs of Lemmas 1 and 2 to show that

$$
\varrho^{L}(z) \equiv\left(\frac{1+\eta g_{0}^{L}}{r+2 \eta}\right)\left(1-\frac{1}{z}\right)-f^{L}(z)
$$

is nonnegative and that $z f^{L}(z)$ is strictly increasing in $z$. If $\bar{T} \leq T_{1}$, we have

$$
f^{1}(\bar{T})=\left(\frac{1+\eta g_{0}^{1}}{r+2 \eta}\right)\left(1-\frac{1}{\bar{T}}\right),
$$

where $f^{1}$ and $g_{0}^{1}$ denote the corresponding quantities for the monopolistic case, since the intermediary does not search at $\bar{T}$. Further,

$$
f^{L}(\bar{T}) \leq\left(\frac{1+\eta g_{0}^{L}}{r+2 \eta}\right)\left(1-\frac{1}{\bar{T}}\right)
$$

from the nonnegativity of $\varrho^{L}(\bar{T})$. Therefore,

$$
\bar{T}\left(f^{1}(\bar{T})-f^{L}(\bar{T})\right) \geq \eta\left(\frac{g_{0}^{1}-g_{0}^{L}}{r+2 \eta}\right)(\bar{T}-1) .
$$

Since $g_{0}^{L} \leq 2 / r$ for any policy, there exists, for any $\varepsilon>0$, some $\bar{\eta}$ such that, for all $\eta<\bar{\eta}$, the right-hand side of (34) is bounded in norm by $\varepsilon$ whenever

\footnotetext{
${ }^{22}$ To verify this, one is to show that $n p_{n} /\left(1-p_{n}\right)$ is decreasing. Expressing $p_{n}$ in terms of $\alpha=(1-\bar{\phi})^{-1}>1$ and letting $x=1 / n$, this is equivalent to showing that $\left(\alpha^{x}-1\right) / x$ is increasing in $x$. This is easily done by checking the positivity of the derivative, whose numerator is increasing in $u=\alpha^{x}$ and vanishes for $u=1$.
} 
$\bar{T} \leq T_{1}$, since we also have an upper bound on $T_{1}$ from (16). Choosing $\varepsilon$ below $(1 / q(n)-1 / q(1)) c$ and setting $\bar{\eta}$ accordingly, we have, for any $\bar{T} \leq T_{1}$,

$$
q(1) \bar{T} f^{1}(\bar{T}) \geq \frac{q(1)}{q(n)}\left(q(n) \bar{T} f^{L}(\bar{T})-q(n) \varepsilon\right) \geq \frac{q(1)}{q(n)}(c-q(n) \varepsilon)>c,
$$

which shows that it is strictly optimal for the monopolist to search at $\bar{T}$, contradicting the assumption that $T \leq T_{1}$.

Q.E.D.

Proof of Proposition 11: At $S_{n}$, it cannot be strictly profitable for an intermediary to deviate by continuing to search and receive the net payoff $q(1) S_{n} f^{L}\left(S_{n}\right)-c$ per unit of effort, but it was profitable to some intermediaries to search at a capital heterogeneity just above $S_{n}$. This implies that $S_{n}$ must satisfy the equation

$$
q(1) S_{n} f^{L}\left(S_{n}\right)=c .
$$

In words, there is a single active intermediary just before $S_{n}$ is reached. We recall from the monopolistic case that $T_{1}$ satisfies the equation

$$
q(1) T_{1} f^{1}\left(T_{1}\right)=c .
$$

Therefore, it suffices to show that the roots of these two equations are arbitrarily close if $\eta$ is arbitrarily small. We have

$$
f^{L}\left(S_{n}\right)=\left(\frac{1+\eta g_{0}^{L}}{r+2 \eta}\right)\left(1-\frac{1}{S_{n}}\right)
$$

and

$$
f^{1}\left(T_{1}\right)=\left(\frac{1+\eta g_{0}^{1}}{r+2 \eta}\right)\left(1-\frac{1}{T_{1}}\right) .
$$

Therefore, $S_{n}$ and $T_{1}$ must satisfy

$$
\left(\frac{1+\eta g_{0}^{L}}{r+2 \eta}\right)\left(S_{n}-1\right)-\left(\frac{1+\eta g_{0}^{1}}{r+2 \eta}\right)\left(T_{1}-1\right)=0,
$$

which may be rewritten as

$$
\left(\frac{1+\eta g_{0}^{L}}{r+2 \eta}\right)\left(S_{n}-T_{1}\right)=\eta\left(\frac{g_{0}^{L}-g_{0}^{1}}{r+2 \eta}\right)\left(1+T_{1}\right) .
$$

Because $T_{1}$ is uniformly bounded from (16) and because both $g_{0}^{L}$ and $g_{0}^{1}$ are bounded by $2 / r$, the right-hand side is less than $\varepsilon$ if $\eta$ is chosen small enough. The first factor of the left-hand side is equivalent to $1 / r$ when $\eta$ is small 
enough. Combining these observations shows that $\left|S_{n}-T_{1}\right| \leq \varepsilon$ for any arbitrary $\varepsilon>0$, provided that $\eta$ is small enough.

Q.E.D.

Appendices D through L are located in Duffie and Strulovici (2012), the Supplemental Material to this paper.

\section{REFERENCES}

Ameriks, J., AND S. Zeldes (2004): "How Do Household Portfolio Shares Vary With Age?" Working Paper, Columbia University. [2493]

ANDRADE, S., C. Chang, AND M. SEASHOles (2008): "Trading Imbalances, Predictable Reversals, and Cross-Stock Price Pressure," Journal of Financial Economics, 88, 406-423. [2494]

AUSUBEL, L. M., AND R. J. DENECKERE (1989): "Reputation in Bargaining and Durable Goods Monopoly," Econometrica, 57, 511-531. [2497]

BARTRAM, S. M., J. GRIFFIN, AND D. NG (2010): "How Important Is Foreign Ownership for International Stock Co-Movement?" Working Paper, Wharton School. [2495]

BASAK, S., AND B. CROITORU (2000): "Equilibrium Mispricing in a Capital Market With Portfolio Constraints," Review of Financial Studies, 13, 715-748. [2470]

BhatTACHARYa, S., AND K. M. HAGERTY (1987): "Dealerships, Trading Externalities, and General Equilibrium," in Contractual Arrangements for Intertemporal Trade. Minnesota Studies in Macroeconomics Series, Vol. 1, ed. by E. Prescott and N. Wallace. Minneapolis: University of Minnesota Press, 81-104. [2470]

Bilias, Y., D. GeORgarakos, AND M. Haliassos (2010): "Portfolio Inertia and Stock Market Fluctuations," Journal of Money, Credit, and Banking, 42, 715-742. [2494]

BORN, P., AND K. VISCUSI (2006): "The Catastrophic Effects of Natural Disasters on Insurance Markets," Journal of Risk and Uncertainty, 33, 55-72. [2493]

BrunNermeIER, M., AND S. NAGEL (2008): "Do Wealth Fluctuations Generate Time-Varying Risk Aversion? Micro-Evidence on Individuals' Asset Allocation," American Economic Review, 98, 713-736. [2494]

ChAISEROTE, S. (2008): "Liquidity Provision by International Institutional Investors: Evidence From Brazilian Privatization," Working Paper, Stanford University. [2495]

CHAN, W. S. (2003): "Stock Price Reaction to News and No-News: Drift and Reversal After Headlines," Journal of Financial Economics, 70, 223-260. [2494]

Chen, H., G. Noronha, AND V. Singhal (2004): "The Price Response to S\&P 500 Index Additions and Deletions: Evidence of Asymmetry and a New Explanation," Journal of Finance, 59, 1901-1929. [2494]

Chen, Z., A. LoOkMAn, And N. SchÜrhoff (2008): "Why Ratings Matter: Evidence From Lehman's Index Inclusion Rule Change,” Working Paper, University of Lausanne. [2494]

COHEN, L., AND D. LOU (2012): “Complicated Firms,” Journal of Financial Economics, 104 (2), 383-400. [2494]

COVAL, J., AND E. STAFFORD (2007): “Asset Fire Sales (and Purchases) in Equity Markets," Journal of Financial Economics, 86, 479-512. [2494,2495]

Dellavigna, S., AND J. M. Pollet (2009): "Investor Inattention and Friday Earnings Announcements," Journal of Finance, 64, 709-749. [2494]

Duffie, D., AND B. STRulovici (2012): "Supplement to 'Capital Mobility and Asset Pricing,", Econometrica Supplemental Material, 80, http://www.econometricsociety.org/ecta/ Supmat/8822_extensions.pdf. [2471,2507]

DufFie, D., N. GÂRLEANU, AND L. H. PEDERSEN (2005): “Over-the-Counter Markets,” Econometrica, 73, 1815-1847. [2470]

(2007): "Valuation in Over-the-Counter Markets," Review of Financial Studies, 20, 1865-1900. [2470] 
ENGelberg, J. E., A. V. ReED, AND M. C. RingGenberg (2012): "How Are Shorts Informed? Short Sellers, News, and Information Processing," Journal of Financial Economics, 105 (2), 260-278. [2494]

EnZ, R. (2001): The Insurance Cycle as an Entrepreneurial Challenge. Zurich, Switzerland: Swiss Re Technical Publishing. [2493]

FeldhÜTteR, P. (2009): “The Same Bond at Different Prices: Identifying Search Frictions and Selling Pressures," Review of Financial Studies, 25, 1155-1206. [2494]

Froot, K. (2001): "The Market for Catastrophe Risk: A Clinical Examination," Journal of Financial Economics, 60, 529-571. [2470]

FroOt, K., AND P. O'CONNELl (1999): “The Pricing of US Catastrophe Reinsurance," in The Financing of Catastrophe Risk, ed. by K. Froot. Chicago, IL: University of Chicago Press, 195-232. [2470,2493]

GEHRIG, T. (1993): "Intermediation in Search Markets," Journal of Economics and Management Strategy, 2, 97-120. [2470]

GreEN, R. (2007): “Issuers, Underwriter Syndicates, and Aftermarket Transparency," Journal of Finance, 62, 1529-1550. [2487]

GReEnwood, R. (2005): "Short and Long Term Demand Curves for Stocks: Theory and Evidence," Journal of Financial Economics, 75, 607-650. [2494]

Gromb, D., AND D. VAYANOS (2012): "Financially Constrained Arbitrage and Cross-Market Contagion," Working Paper, London School of Economics. [2470]

HARRIS, L., AND E. GUREL (1986): "Price and Volume Effects Associated With Changes in the S\&P 500: New Evidence of Price Pressures," Journal of Finance, 41, 815-830. [2494]

HE, Z., AND A. KRISHnAmurThy (2012): "A Model of Capital and Crises," Review of Economic Studies, 79 (2), 735-777. [2470]

Holthausen, R. W., R. LeFtwich, AND D. Mayers (1990): "Large-Block Transactions, the Speed of Response and Temporary and Permanent Stock-Price Effects," Journal of Financial Economics, 26, 71-95. [2494]

HRADSKY, G. T., AND R. D. LONG (1989): "High-Yield Default Losses and the Return Performance of Bankrupt Debt," Financial Analysts Journal, 45, 38-49. [2494]

KAUl, A., V. Mehrotra, AND R. MorcK (2000): "Demand Curves for Stocks do Slope Down: New Evidence From an Index Weights Adjustment,” Journal of Finance, 55, 893-912. [2494]

KULAK, J. P. (2008): "Price-Pressures and Foreign Investor Biases Revealed Through Firms: Geographical Placement Choices," Working Paper, University of Lausanne. [2494]

LAGOS, R., G. RocheteAU, AND P. WeILl (2011): "Crises and Liquidity in Over-the-Counter Markets," Journal of Economic Theory, 146, 2169-2205. [2470]

LOU, D. (2009): "A Flow-Based Explanation for Return Predictability," Working Paper, Yale University, Review of Financial Studies (forthcoming). [2495]

LuSARDI, A. (1999): "Information, Expectations, and Savings," in Behavioral Dimensions of Retirement Economics, ed. by H. Aaron. Washington, DC: Brookings Institution Press, 81-115. [2494]

College. [2494]

MAILATH, G., AND L. SAMUELSON (2006): Repeated Games and Reputations: Long-Run Relationships. Oxford, U.K.: Oxford University Press. [2497]

Mitchell, M., L. H. Pedersen, And T. Pulvino (2007): "Slow Moving Capital," American Economic Review, Papers and Proceedings, 97, 215-220. [2494]

Mitchell, O. S., G. R. Mottola, S. P. UtKus, AND T. Yamaguchi (2006): “The Inattentive Participant: Portfolio Trading Behavior in 401(k) Plans," Working Paper, University of Pennsylvania. [2493]

MORESI, S. (1991): “Three Essays in Economic Theory,” Ph.D. Thesis, MIT. [2470]

MoU, Y. (2011): "Limits to Arbitrage and Commodity Index Investment: Front-Running the Goldman Roll,” Working Paper, Columbia University. [2494] 
NEWMAN, Y., AND M. RIERSON (2003): "Illiquidity Spillovers: Theory and Evidence From European Telecom Bond Issuance," Working Paper, Graduate School of Business, Stanford University. [2494]

ProtTer, P. (2004): Stochastic Integration and Differential Equations (Second Ed.). New York: Springer-Verlag. [2472]

QUAH, J., AND B. STRULOVICI (2009): "Comparative Statics, Informativeness, and the Interval Dominance Order," Econometrica, 77, 1949-1992. [2483]

[2483] (2012): "Discounting, Values, and Decisions," Working Paper, Northwestern University.

RUBInSTEIN, A. (1982): “Perfect Equilibrium in a Bargaining Model,” Econometrica, 50, 97-108. [2488]

RUBinsteIn, A., AND A. WOLINSKY (1987): "Middlemen,” Quarterly Journal of Economics, 102, 581-594. [2470]

SCHOLES, M. (1972): “The Market for Securities: Substitution versus Price Pressure and the Effects of Information on Share Prices," Journal of Business, 45, 179-211. [2494]

ShleIfER, A. (1986): "Do Demand Curves for Stocks Slope Down?” Journal of Finance, 41, 579-590. [2494]

StOle, L., AND J. ZwiEBel (1996): "Intra-Firm Bargaining Under Non-Binding Contracts," Review of Economic Studies, 63, 375-410. [2488]

Sun, Y. (2006): "The Exact Law of Large Numbers via Fubini Extension and Characterization of Insurable Risks," Journal of Economic Theory, 126, 31-69. [2475]

SuTTON, J. (1986): "Non-Cooperative Bargaining Theory: An Introduction," Review of Economic Studies, 53, 709-724. [2487]

VAYANOS, D., AND T. WANG (2007): "Search and Endogenous Concentration of Liquidity in Asset Markets," Journal of Economic Theory, 136, 66-104. [2470]

WeILl, P.-O. (2007): "Leaning Against the Wind," Review of Economic Studies, 74, 1329-1354. [2475]

(2008): “The Liquidity Premium in a Dynamic Bargaining Market," Journal of Economic Theory, 140, 66-96. [2470]

YAVAS,, A. (1996): "Search and Trading in Intermediated Markets," Journal of Economics and Management Strategy, 5, 195-216. [2470]

ZANJANI, G. (2002): "Pricing and Capital Allocation in Catastrophe Insurance," Journal of Financial Economics, 65, 283-305. [2493]

Graduate School of Business, Stanford University, Stanford, CA 94305, U.S.A.; duffie@stanford.edu

and

Dept. of Economics, Northwestern University, Evanston, IL 60208, U.S.A.; b-strulovici@northwestern.edu.

Manuscript received September, 2009; final revision received January, 2012. 